\title{
Understanding the performance losses and "invasiveness" of in situ characterization steps during carbon corrosion experiments in polymer electrolyte membrane fuel cells
}

\author{
Fengmin Du ${ }^{\mathrm{a}, \mathrm{b}, *}$, Tuan Anh Dao ${ }^{\mathrm{a}}$, Andreas Bauer ${ }^{\mathrm{a}}$, Michael Obermaier ${ }^{\mathrm{a}}$, \\ Thomas J. Schmidt ${ }^{\mathrm{b}, \mathrm{c}}$, Alin Orfanidi ${ }^{\mathrm{a}}$ \\ a BMW Group, Munich D-80788, Germany \\ ${ }^{\mathrm{b}}$ Laboratory for Physical Chemistry, ETH Zurich, Zurich $\mathrm{CH}-8093$, Switzerland \\ ${ }^{\mathrm{c}}$ Electrochemistry Laboratory, Paul Scherrer Institute, Villigen PSI, Villigen, CH-5232, Switzerland
}

\section{A R T I C L E I N F O}

\section{Article history:}

Received 3 August 2021

Revised 5 October 2021

Accepted 2 November 2021

Available online 8 November 2021

\section{Keywords:}

Polymer electrolyte membrane fuel cell

Cathode catalyst layer degradation

Carbon corrosion

Polarization performance

Voltage loss analysis

\begin{abstract}
A B S T R A C T
Carbon corrosion represents one of the most critical degradation mechanisms within state-of-the-art polymer electrolyte membrane fuel cells. Its most prominent consequences include the loss of electrochemical active surface area (ECSA), porosity, and electrical contact within the electrode. The present study seeks a detailed understanding of the dependence between the polarization performance losses and the individual loss terms, both as a function of the amount of corroded carbon. A simplified onedimensional polarization model is developed with the aim to simulatively reconstruct the empirical polarization curve based on in situ cell characteristics during the course of carbon corrosion. It is shown that this model enables the assignment of nearly all voltage losses at various stages of the corrosion process, up to a cell current density of around $2 \mathrm{~A} \mathrm{~cm}^{-2}$. Furthermore, the "observer effect" during the carbon corrosion studies is investigated, where it is demonstrated that the application of characterization steps exerts strong adverse effects on the ECSA. This is explained by the "voltage cycling" conditions which are inevitably introduced during the characterization protocols, part of which is conducted under cell voltage as low as $0.2 \mathrm{~V}$.
\end{abstract}

(c) 2021 Elsevier Ltd. All rights reserved.

\section{Introduction}

Over the last decade, growing concerns on global climate change have been triggering increasingly stringent regulations of greenhouse gas emissions in the transportation sector, necessitating the search for elaborate technologies to electrify daily commutes, transport of goods and recreational travel [1]. Among the available options, fuel cell electric vehicles (FCEVs) have shown great promises with their zero emission, alongside with the capabilities of long driving ranges and fast refueling characteristics. Nonetheless, FCEVs remain currently in their early stage of commercialization [2,3], where the durability of their core component, namely polymer electrolyte membrane fuel cells (PEMFCs), still remains as one of the main bottlenecks $[2,4,5]$.

While durability issues exist for almost all PEMFC components, the cathode catalyst layer $(\mathrm{CL})$ can be regarded as the most critical in this respect, as it directly relates to the electrochemical per-

\footnotetext{
* Corresponding author at: BMW Group, Munich D-80788, Germany.

E-mail address: dufe@student.ethz.ch (F. Du).
}

formance of the fuel cell [6]. At the same time, the cathode CL is one of the PEMFC components that is the most prone to degradation [7]. A number of mechanisms are well-known in the literature, including but not limited to Pt dissolution [2,8-10], ionomer redistribution/degradation [11,12], and carbon corrosion [4,13,14]. The present study focuses on carbon corrosion at increased cathode potentials (e.g. during fuel starvation events), which typically causes severe performance losses in the PEMFCs within short period of time [15].

In state-of-art PEMFCs, high-surface area carbon (HSAC) is commonly utilized in the catalyst layers (CLs) as catalyst support. It is well known that carbon on the PEMFC cathode is thermodynamically prone to oxidation, yet its slow kinetics keeps the total loss over the fuel cell lifetime insignificant $[4,16]$. However, if the fuel cell runs into startup/shutdown (SUSD) condition or suffers from hydrogen starvation due to e.g. anode flooding, the local potential on the cathode may be further elevated (up to $1.4-1.5 \mathrm{~V}$ vs. RHE) to accelerate carbon corrosion, possibly leading to significant carbon loss within minutes $[15,17,18]$. In consequence, additional kinetic, ohmic, and mass transport related losses are induced within the PEMFC. The kinetic losses are primarily caused by the detachment 
of Pt particles within the cathode $\mathrm{CL}$ with the consequence of a reduced electrochemical active surface area (ECSA) [19-22]. ECSA losses caused by Pt particle agglomeration as a result of carbon corrosion have also been reported $[19,23,24]$. On the other hand, ohmic losses increase due to the deteriorating electrical contact between the CL and the gas diffusion layer (GDL) [25], as well as distortion in protonic contact between the $\mathrm{CL}$ and the membrane upon cathode thinning [26]. Additionally, the reduction in CL porosity impairs $\mathrm{O}_{2}$ mass transport [14,27]. Collapse of carbon structure was reported to strongly increase mass transport resistances of the fuel cell and detrimentally affect the PEMFC performance $[12,28]$. Further adverse effects of carbon corrosion on the MEA include ionomer redistribution and thus disturbances in the protonic conductive pathway [12], as well as an increase in CL hydrophilicity which would lead to cell flooding issues [29-31].

The abovementioned observations raise the question of how performance or voltage losses of the MEA, measured in a polarization curve, are quantitatively correlated with carbon corrosion. This question, however, complicates itself in the way that the extent of carbon corrosion has a wide variety of definitions. In most of related studies, this extent is defined exclusively by the number of applied accelerated stress test (AST) cycles. Relevant cycles are typically conducted either via cathode potential cycling (typical upper boundary amounts to 1.4 or $1.5 \mathrm{~V}$ vs. RHE and the lower boundary 0.6 or $1.0 \mathrm{~V}$ vs. RHE) [19,20,22,32,33], potential holding at a point between 1.2 and $1.5 \mathrm{~V}$ vs. RHE [26,34], a combination of both [35], or through SUSD protocols [13,25,36,37]. However, even within the same category, the degradation protocols in these studies have not been identical. It is additionally known that the protocol itself (e.g. which voltage cycle profile was selected) may change the observed activity and ECSA losses [27,38]. With a vast variety of AST/SUSD protocols applied in the literature, it becomes hard to compare across the studies, since the correlation of performance losses between tests applying different AST/SUSD cycles is very vague.

One suitable option for the comparability across different studies is to use the amount of lost carbon (or its respective weight percentage in comparison to the total amount of carbon) as the benchmarking variable. It shall be noticed that this is not the sole influential factor during the carbon corrosion tests, yet it offers a very straightforward and intuitive way to compare among carbon corrosion studies. An additional advantage lies in that the corrosion amount can be more easily linked to starvation-related studies, where carbon corrosion currents/charges are usually reported $[17,39,40]$. Generally speaking, carbon loss can be experimentally quantified by conducting $\mathrm{CO}_{2}$ measurements from the cathode outlet, either through mass spectrometry $[13,19,32,41,42]$, infrared analyzer/spectroscopy [33,34,36,43] or gas chromatography [16]. Nonetheless, only a few studies have reported the amount of carbon lost during their applied AST cycles. For instance, Mittermeier et al. reported carbon corrosion rate (in A per gram carbon) in dependence of the applied potential (between 1.1 and $1.5 \mathrm{~V}$ vs. RHE) [13], while Fang et al. showed the carbon loss (in $\mu \mathrm{g} \mathrm{cm}^{-2}$ or in wt\%) after a variety of ASTs [27]. An evaluation of fuel cell performance losses combined with the measurement of actual carbon loss was performed by Hashimasa et al. (on three different AST protocols) [34] and Yu et al. (on potential holding) [16,44].

An additional aspect related to the cell degradation is how the overall performance losses can be explained by the changes of various in situ electrochemical characteristics of the cell. For this purpose, the general "voltage loss analysis" methodology may be applied $[8,45,46]$, where the individual known types of PEMFC voltage losses (i.e. kinetic, ohmic, and mass transport related losses) are quantitatively correlated with cell characteristics (see Refs. $[45,46]$ for typical calculation formulae). To the best of our knowledge, such an approach in investigating the cell performance losses has not been reported on carbon corrosion studies so far, where most studies only focused on single aspect of these characteristics (typically kinetic aspects related to ECSA and mass activity). Nonetheless, it shall be noted that within empirical PEMFC studies, voltage loss analysis has been reported to possibly leave a relatively significant fraction of unaccounted losses (up to the order of $100 \mathrm{mV}$ ) $[45,47]$.

In the present study, the performance losses related to carbon corrosion within a PEMFC are systematically investigated. The experimental protocol includes a set of pre-tests with pure carbon cathodes, where the current responses are compared with those on the Pt/C MEA, thus allowing the quantification of carbon loss during the testing protocol. By conducting detailed in situ electrochemical characterizations over the course of several carbon corrosion AST cycles, the polarization curves before/after the corrosion are reconstructed using a simplified $1 \mathrm{D}$ model that accounts for kinetic, ohmic and mass transport related voltage loss terms. A comparison of this modeled polarization curve with the experimentally obtained one verifies the accuracy of this reconstruction in the current density region up to $2 \mathrm{~A} \mathrm{~cm}^{-2}$. Furthermore, by comparing results from different test sequences during corrosion cycles, it is demonstrated that the in situ characterization protocols themselves have a relatively strong influence on the degradation within the MEA. This "observer effect" during carbon corrosion studies shall be paid great attention to, in order to avoid misinterpretation of experimental results.

\section{Experimental}

\subsection{Membrane electrode assembly preparation}

The membrane electrode assemblies (MEAs) used in the present study were prepared by the decal transfer method [48], with the electrodes manufactured in-house according to previous publications of the authors $[11,49]$. Two sets of cathodic electrodes were prepared: one comprises 50wt\% Pt/C (carbon support Ketjen EC300J with around 30\% of the Pt particles located outside the carbon porous structure; supplied by Johnson Matthey), the other with no Pt (only carbon support Ketjen EC300J). All of the anodic electrodes consisted of 30wt\% Pt on graphitized Ketjen Black (TEC10EA30E; purchased from Tanaka Kikinzoku). The ionomer (ionomer type: $725 \mathrm{EW}, 3 \mathrm{M}$ ) to carbon weight ratios $(\mathrm{I} / \mathrm{C})$ were set to 0.82 for all cathodic electrodes and 1.0 for the anodic ones.

The real Pt loading of the Pt/C cathodic electrodes was $0.33 \pm$ $0.02 \mathrm{mg}_{\mathrm{Pt}} / \mathrm{cm}^{2}$ geo. All the anodes showed loadings in the range of $0.04-0.06 \mathrm{mg}_{\mathrm{Pt}} / \mathrm{cm}^{2}$ geo. All loadings were determined by weighing the decal before and after the catalyst layer transfer.

MEAs of $8.25 \mathrm{~cm}^{2}$ size were assembled by hot-pressing (conditions: $155^{\circ} \mathrm{C}, 3 \mathrm{~min}$, applied force of $0.24 \mathrm{kN} / \mathrm{cm}^{2}$ ) the anode decal, a $10 \mu \mathrm{m}$ membrane (Gore MX20.10) and the cathode decal. Thereafter, the MEAs were laminated between two sub-gaskets $(200 \times 200 \mathrm{~mm}, 25 \mu \mathrm{m}$ PEN-foil CMC 61325 coated with a heat activated adhesive ( $\sim 15 \mu \mathrm{m}$ thick); CMC Klebetechnik), leaving an actual active area of $5 \mathrm{~cm}^{2}(50 \times 10 \mathrm{~mm})$. Fig. S1 depicts a laminated and framed MEA.

\subsection{Fuel cell operation and corrosion cycle}

All in situ electrochemical measurements were conducted within a modified single-cell hardware (Tandem Technologies Ltd.), fitted within a graphite composite flow field (area: $50 \mathrm{~cm}^{2}$ geo ) with 14 serpentine channels $(\approx 0.5 \mathrm{~mm}$ lands/channels; purchased by Nisshinbo). The compression of the gas diffusion media (SGL 29BC on both sides) was set to $20 \%$ by using incompressible fiber-glass PTFE sub-gaskets (Fiberflon) and applying a clamping force of 15.2 $\mathrm{kN}$. The MEA was placed at the end of the flow channels (similar to 
a)

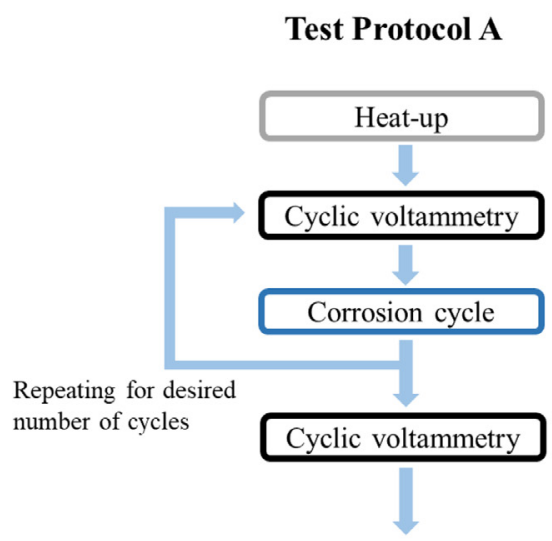

End of test

\section{Test Protocol B}

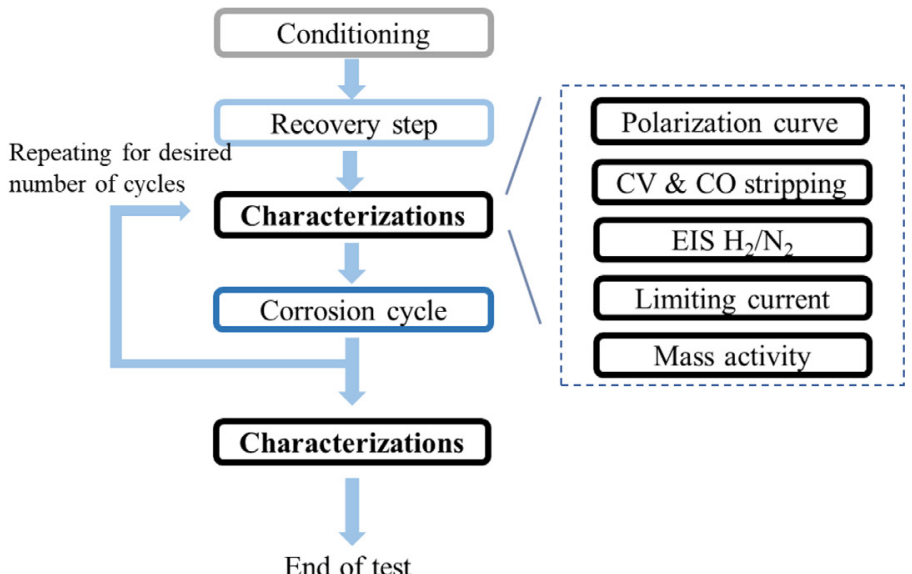

End of test

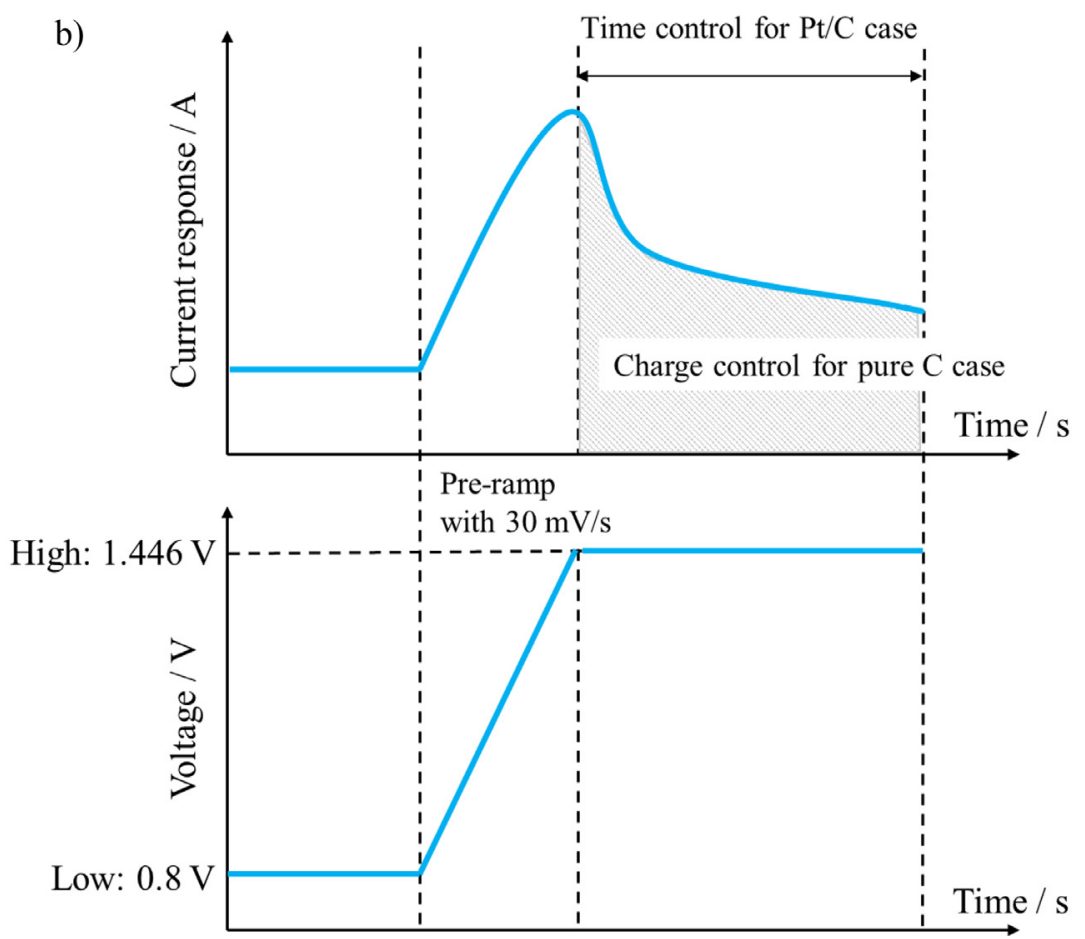

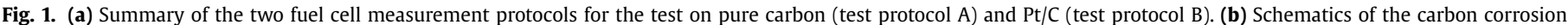

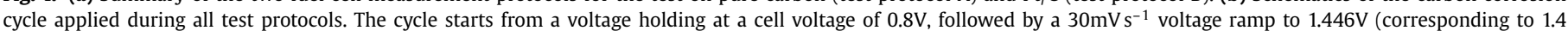

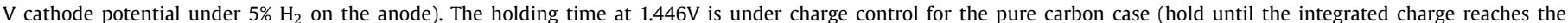
target value) and time control for the Pt/C case (hold for the same time as it was determined during the corresponding pure carbon experiment).

Baker et al. [50], additionally illustrated in Fig. S2), while the rest of the flow field was masked, preventing cross-channel convection. This configuration ensures that under all relevant operating conditions, the maximum pressure drop is $<1 \mathrm{kPa}$ over the entire active area $\left(5 \mathrm{~cm}^{2}\right)$ and therefore the mass transport of the reactant gases is driven by diffusion and not by convection.

The tests were performed on a single cell test station (HORIBA FuelCon $\mathrm{GmbH}$ ), utilizing pure hydrogen (99.999\% purity) as the anode reactant and compressed air as the cathode reactant. A potentiostat coupled with a booster (ZAHNER-Elektrik GmbH \& CoKG) was used to control the cell potential/current.

Two test protocols were used (see Fig. 1a): one for the pre-test with pure carbon cathodes (protocol A) and one for the Pt/C MEAs (protocol B). In both protocols, the same carbon corrosion cycle was applied, where the cell was kept at a temperature of $80^{\circ} \mathrm{C}$, a back pressure of $150 \mathrm{kPa}($ abs.) and a relative humidity ( $\mathrm{RH})$ of 95 $\%$. The mixture of $0.15 \mathrm{NL} \mathrm{min}^{-1} \mathrm{H}_{2}$ and $2.85 \mathrm{NL} \mathrm{min}^{-1} \mathrm{~N}_{2}\left(5 \% \mathrm{H}_{2}\right.$ in $\mathrm{N}_{2}$ ) was used as anode feed gas, whereas the cathode gas was set to $2.0 \mathrm{NL} \mathrm{min}^{-1}$ air. The application of air on the cathode side represents realistic conditions in automotive PEMFCs, however it has to be mentioned that $\mathrm{N}_{2}$ is also widely used in literature carbon corrosion protocols. In the Supplementary Material (Fig. S11 and Table S4), a preliminary test case is shown which confirms that under the present test conditions, employing $\mathrm{N}_{2}$ or air environment on the cathode side hardly affects the results.

During the corrosion cycle, the cell voltage was held at $0.8 \mathrm{~V}$ for $5 \mathrm{~min}$ (with the aim to oxidize the Pt surface in the Pt/C case) and thereafter ramped to $1.446 \mathrm{~V}$ with a rate of $30 \mathrm{mV} \mathrm{s}^{-1}$. The value of 
$1.446 \mathrm{~V}$ was chosen as the target cell voltage as it corresponds to a cathode potential of $1.4 \mathrm{~V}$ vs. RHE under diluted $\mathrm{H}_{2}$ on the anode side $\left(5 \% \mathrm{H}_{2}\right.$ corresponds to $-46 \mathrm{mV}$ Nernst shift on the anode side). The value of $1.4 \mathrm{~V}$ has the rationale that it is close to the cathode potential under local hydrogen starvation conditions [51,52] and is sufficiently high to keep the test duration short [23]. At the same time, this potential is not high enough to induce significant contribution of oxygen evolution reaction (OER) on Pt (which may lead to mechanical detachment of carbon particles) [51]. The applied voltage ramp prior to the potential holding reduces the influence of double-layer charging on the current response during the subsequent voltage holding, without introducing significant degradation to the MEA (total ramping time $\approx 21 \mathrm{~s}$, where the time over $1.3 \mathrm{~V}$ cathode potential is only $3 \mathrm{~s}$ ).

During protocol $\mathrm{A}$, the cell was held at $1.446 \mathrm{~V}$ until the integrated charge during this stage (see shaded area in Fig. 1b) reaches the corresponding target percentage of carbon corrosion (e.g. for 8 wt\% carbon loss at a loading of $0.32 \mathrm{mg}_{\mathrm{C}} \mathrm{cm}^{-2}$, the target total charge during voltage holding amounts to $4.12 \mathrm{C}$ ). By using a pure carbon cathode, reactions occurring parallel to carbon corrosion (i.e. Pt oxidation, oxidation of crossover $\mathrm{H}_{2}$, and OER) are eliminated. Thus, the measured charge corresponds to the carbon corrosion charge with small errors due to double-layer charging effect, where the latter is further minimized by the pre-ramping step. The use of pure carbon electrodes therefore offers a method to correlate the corrosion time with the amount of corroded carbon without the need for $\mathrm{CO}_{2}$ emission measurement.

During protocol $\mathrm{B}$, the cell was held at $1.446 \mathrm{~V}$ for the same duration as it is the case during the pure carbon experiment. It is known that the catalyzing effect of Pt on carbon corrosion is negligible at a cathode potential over $1.1 \mathrm{~V}$ vs. RHE as Pt is passivated by the formation of an oxide layer [33]. Thus, by applying very similar carbon loading in pure carbon and $\mathrm{Pt} / \mathrm{C}$ cathode, the carbon corrosion rate on both types of electrodes is expected to be the same. This leads to the same percentage of carbon loss at the end of the corrosion cycle (say, 8wt\%) for both electrode types. A detailed analysis of the current responses during the corrosion cycles is given in the Supplementary Material (section "Current responses during corrosion cycles on pure carbon and Pt/C cathodes").

In both protocols, characterization steps were introduced at beginning-of-life (BOL) and repeated after each of the corrosion cycles (refer to Fig. 1a). For test protocol A, applied to pure carbon electrodes, the characterization comprised only one cyclic voltammetry measurement $\left(80^{\circ} \mathrm{C}, 95 \% \mathrm{RH}\right.$, ambient pressure, $0.053-1.0 \mathrm{~V}$ with $50 \mathrm{mV} \mathrm{s}^{-1}$ ) which reveals the change of the double-layer capacitance over the corrosion course.

In test protocol $\mathrm{B}$, applied to $\mathrm{Pt} / \mathrm{C}$ cathodes, the MEA was first conditioned, followed by a short recovery step (2h), eliminating possible influence of reversible voltage losses on the BOL performance. The subsequent characterization block consisted of $\mathrm{H}_{2}$ /air polarization curve, $\mathrm{CO}$ stripping, limiting current, EIS in $\mathrm{H}_{2} / \mathrm{N}_{2}$, as well as $\mathrm{H}_{2} / \mathrm{O}_{2}$ polarization curve (details see Section 2.4). The MEA was thereafter subjected to the corrosion cycles. The characterization block was repeated after each of the corrosion cycle.

\subsection{Conditioning and recovery step}

All MEAs were conditioned prior to in situ testing under $\mathrm{H}_{2}$ /air flows $\left(1.0 / 2.0 \mathrm{NL} \mathrm{min}^{-1}\right), 80^{\circ} \mathrm{C}, 100 \% \mathrm{RH}$ and $170 \mathrm{kPa}$. The following voltage-controlled sequence was repeated 10 times: $0.55 \mathrm{~V}$ for 45 min, open-circuit voltage (OCV) for $30 \mathrm{~s}$, and $0.85 \mathrm{~V}$ for $10 \mathrm{~min}$ [11].

After conditioning, the MEAs were subjected to a short recovery step, which aims to eliminate influences of possible reversible losses prior to the BOL characterization steps. The recovery was conducted at $45^{\circ} \mathrm{C}$ and $100 \% \mathrm{RH}$ for $2 \mathrm{~h}$, utilizing a diluted air flow $\left(8.6 \% \mathrm{O}_{2}, 0.7 \mathrm{NL} \mathrm{min}{ }^{-1}\right.$ air $\left.+1.0 \mathrm{NL} \mathrm{min}^{-1} \mathrm{~N}_{2}\right)$, similar to the authors' previous publication [11].

\subsection{Characterization steps}

All characterizations were conducted under differential flows at a cell temperature of $80^{\circ} \mathrm{C}$ and a relative humidity of $90 \%$ on both anode and cathode sides (besides the mass activity determination which was conducted at $100 \% \mathrm{RH}$ ). It shall be mentioned that all given cell pressures refer to their absolute values at cell outlet. For more details about the experimental specifications, please refer to the authors' recent publication [11].

The $\mathrm{H}_{2}$ /air polarization curves were acquired under $170 \mathrm{kPa}$ and constant differential flows of $\mathrm{H}_{2}$ /air at $1.0 / 2.0 \mathrm{NL} \mathrm{min}^{-1}$. High frequency resistances (HFRs) were determined by collecting alternating current $(A C)$ impedance spectra at various current densities. Thereafter, CO stripping was performed at ambient pressure to evaluate the electrochemical active surface area (ECSA) of the MEA.

The next step of the characterization is electrochemical impedance spectroscopy (EIS) in $\mathrm{H}_{2} / \mathrm{N}_{2}$ with potentiostatic control at $0.5 \mathrm{~V}$. Contrary to the transmission line model applied in Ref. [11], the proton resistance of the cathode CL was estimated by means of a manual fitting (details and rationale see the Supplementary Material). Furthermore, the values from this manual fitting were left in $\Omega \cdot \mathrm{cm}^{2}$ (see also in Fig. 4) as the electrode thickness is unknown a priori, despite the standard practice of giving the proton resistivities in $\Omega \cdot \mathrm{cm}$.

Subsequently, the total mass transport resistance of $\mathrm{O}_{2}$ was determined from limiting current measurements with diluted air $(4 \%$ $\mathrm{O}_{2}$ ). The procedure was repeated at three different total pressures: 170,230 and $300 \mathrm{kPa}$, allowing the deconvolution of pressuredependent $\left(R_{\mathrm{PD}}\right)$ and pressure-independent terms $\left(R_{\mathrm{PI}}\right)$ of the total resistances according to Baker et al. [50].

Lastly, the mass activity was determined (contrary to the protocol in Ref. [11]) via $\mathrm{H}_{2} / \mathrm{O}_{2}$ polarization curve, obtained at $80^{\circ} \mathrm{C}$, $100 \% \mathrm{RH}$ and $150 \mathrm{kPa}$ under constant differential flows of $\mathrm{H}_{2} / \mathrm{O}_{2}$ $\left(1.0 / 2.0 \mathrm{NL} \mathrm{min}^{-1}\right)$. The current density of the cell was set from high to low $\left(0.8 \mathrm{~A} \mathrm{~cm}^{-2}\right.$ to $\left.\mathrm{OCV}\right)$ while the cell voltage was recorded. Each current density point was held for $2 \mathrm{~min}$ (with the exception at $0.05,0.1,0.15,0.2$ and $0.25 \mathrm{~A} \mathrm{~cm}^{-2}$ with 30 s holding time each). The points were repeated once for reproducibility. For the evaluation of the mass activity, the HFR and the $\mathrm{H}_{2}$ crossover are first to be corrected from the measured polarization curve. The logarithm of current density was subsequently plotted against the cell voltage (i.e. Tafel plot), where a linear fit can be found for the current density points between 0.2 and $0.5 \mathrm{~A} \mathrm{~cm}^{-2}$ and extrapolated to a cell voltage of $0.9 \mathrm{~V}$ (Tafel line). The mass activity corresponds to the current density value at $0.9 \mathrm{~V}$, normalized to the nominal $\mathrm{Pt}$ loading (values in $\mathrm{A} \mathrm{mg}_{\mathrm{Pt}}{ }^{-1}$ ).

\subsection{Test sequences}

Table 1 summarizes the test sequences used in the present study. This study first focuses on corrosion cycles with 8 wt\% nominal carbon loss per cycle, where either three, four, or five cycles were applied during the test protocol. Thereafter, single-cycle corrosion was conducted (with 24,32 or $40 \mathrm{wt} \%$ nominal carbon loss per cycle) to shed light onto the influence of the characterizations themselves on the performance losses (refer to discussions in Section 4.6). To ensure reproducibility, each test sequence was conducted on two individual MEAs. It shall be noted that some "MEA states" are shared by multiple test sequences and characterized accordingly (refer to the last column of Table 1: for instance, BOL-characterizations were conducted on all 12 MEAs; MEA No. 1-6 all had the characterization step after one, two, or three 8 
Table 1

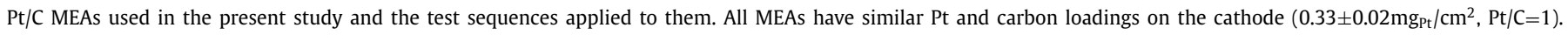
All six test sequences were repeated once for reproducibility.

\begin{tabular}{|c|c|c|c|}
\hline MEA No. & Corrosion cycle (nominal carbon loss) & Total number of cycles & In situ characterizations done at: (type of corrosion cycle) $\times($ number $)$ \\
\hline $1-2$ & $8 w t \%$ & Three (total 24\%) & BOL, $8 \% \times 1,8 \% \times 2,8 \% \times 3$ \\
\hline $3-4$ & $8 w t \%$ & Four (total 32\%) & BOL, $8 \% \times 1,8 \% \times 2,8 \% \times 3,8 \% \times 4$ \\
\hline $5-6$ & $8 w t \%$ & Five (total $40 \%$ ) & BOL, $8 \% \times 1,8 \% \times 2,8 \% \times 3,8 \% \times 4,8 \% \times 5$ \\
\hline $7-8$ & $24 \mathrm{wt} \%$ & Single & BOL, $24 \% \times 1$ \\
\hline $9-10$ & $32 w t \%$ & Single & BOL, $32 \% \times 1$ \\
\hline $11-12$ & $40 w t \%$ & Single & BOL, $40 \% \times 1$ \\
\hline
\end{tabular}

wt\%-corrosion cycles). The experimental values shown in the Results section correspond to the average of the measurements, with the error bars depicted as their standard deviation.

\subsection{Postmortem analysis}

One MEA from each test sequence was subjected to postmortem analysis at the end of the test protocol (end-of-life, EOL). After carefully removing the GDL from the used MEAs, crosssections were prepared using a Cryo Cross Section Polisher (JEOL IB-19520CCP), followed by analyzing the electrode thicknesses and morphology with digital 3D-light microscopy (Keyence VHX-6000). Images with high resolution were obtained via scanning electron microscopy (SEM, Zeiss SUPRA 55 VP with field emission electron gun and variable pressure), using backscattered electrons (BSE) with an accelerating voltage of $5 \mathrm{kV}$. Energy-dispersive X-ray spectroscopy (EDX, 10kV) was additionally performed to detect possible presence of $\mathrm{Pt}$ in the membrane.

\section{Calculations/modeling}

With detailed in situ/ex situ electrochemical characteristics (including ECSA, mass activity, HFR, CL protonic conductivity and electrode thickness) available, we aim to reconstruct the experimental polarization curve using these parameters. This is expected to provide valuable insights towards how well the performance losses can be correlated with individual electrochemical characteristics of the MEA.

Here, a one-dimensional through-plane model is utilized to simulate the polarization performances. The model focuses on the catalyst-coated membrane (CCM) domain, consisting of the anode $\mathrm{CL}$, the membrane, and the cathode $\mathrm{CL}$. Transport phenomena of $\mathrm{H}_{2}, \mathrm{O}_{2}$, electrons and protons are taken into consideration in the form of a one-dimensional (coordinate $y$ refers to the throughplane direction of the $\mathrm{CCM}$ ), stationary ordinary differential equation system. Note that the 1D model is "simplified" as it does not account for water transport phenomena through the CCM. In the cathode CL, the transport equations take form of Eqs. (1), (2):

$D_{\mathrm{O}_{2}} \frac{\partial^{2} c_{\mathrm{O}_{2}}}{\partial y^{2}}+\frac{i_{\mathrm{V}}}{4 F}=0$

$\sigma_{\mathrm{e}} \frac{\partial^{2} \varphi_{\mathrm{e}}}{\partial y^{2}}-i_{\mathrm{V}}=0 ; \sigma_{\mathrm{p}} \frac{\partial^{2} \varphi_{\mathrm{p}}}{\partial y^{2}}+i_{\mathrm{V}}=0$

Here, $c_{\mathrm{O}_{2}}, \varphi_{\mathrm{e}}$, and $\varphi_{\mathrm{p}}$ refer to the local oxygen concentration, the electric potential and the protonic potential, respectively. $D_{\mathrm{O}_{2}}$ is the oxygen diffusivity which accounts for the Knudsen diffusion within the porous volume of the cathode $\mathrm{CL}$, while $\sigma_{\mathrm{e}}$ and $\sigma_{\mathrm{p}}$ denote the electric and protonic specific conductivity within the CL. $F$ is the Faraday constant $\left(96,485 \mathrm{Cmol}^{-1}\right)$.

The volumetric current density term of the oxygen reduction reaction (ORR), $i_{\mathrm{V}}$, is evaluated by the generalized Butler-Volmer equation, where the electrode potential corresponds to the local difference of electric and protonic potential (i.e. $\varphi_{\mathrm{e}}-\varphi_{\mathrm{p}}$ ). The details on this calculation are documented in the Supplementary Material (section "Modeling details"). Overall, the simplified model applies a macro-homogeneous approach in the CL [53] which assumes that the active sites are homogeneously distributed over the thickness of the CL. Nonetheless, a correction term was implemented in the ORR kinetics to account for the extra $\mathrm{O}_{2}$ transport resistance at the $\mathrm{Pt} /$ ionomer interface:

$i_{\mathrm{V}}=\frac{i_{\mathrm{V}, \text { kin }}}{1+\frac{k \cdot R_{\mathrm{Pt} / \mathrm{ion}}}{4 F \cdot a}} ; \quad k=\frac{i_{\mathrm{V}, \mathrm{kin}}}{c_{\mathrm{O}_{2}}}$

In Eq. (3), $i_{\mathrm{V}, \text { kin }}$ denotes the volumetric current density from the Butler-Volmer equation (thus purely kinetic). $R_{\mathrm{Pt} / \text { ion }}$ is the resistance at the Pt/ionomer interface (unit: $\mathrm{s} \mathrm{cm}^{-1}$, based on the Pt surface area) and $a$ the specific Pt area per unit CL volume $\left(\mathrm{cm}^{2} \mathrm{~cm}^{-3}\right)$. The derivation of this equation is elaborated in the Supplementary Material (equation (S11)-(S13)).

With the 1D CCM model, the following voltage loss terms within the MEA can already be taken into account:

- Kinetic losses, majorly due to ORR.

- Electric/protonic resistances throughout the CCM, including the membrane resistance as part of the HFR.

- $\mathrm{O}_{2}$ diffusion resistance in the porous volume of the cathode $\mathrm{CL}$ as well as at the Pt/ionomer interface.

- $\mathrm{O}_{2}$ transport resistance outside the cathode CL (by applying an appropriate boundary condition on the GDL side for $\mathrm{O}_{2}$ transport, see Supplementary Material, Table S2), which is assumed to be equal to the pressure-dependent term of $\mathrm{O}_{2}$ transport resistance ( $R_{\mathrm{PD}}$, see Section 4.4).

Therefore, the CCM model requires only a minor correction term for the remaining HFR induced by the GDL and contact resistances. This term corresponds to the experimentally obtained HFR subtracted by the membrane resistance applied in the CCM. Details on this correction procedure are described in the Supplementary Material (Fig. S4). Lastly, the influence of $\mathrm{H}_{2}$ crossover on the polarization performance is accounted for by subtracting the output current density by the experimentally obtained crossover value.

\section{Results and discussion}

\subsection{Experimental polarization performances}

Fig. 2 compares the polarization performances at BOL or after 1-5 corrosion cycles with $8 \mathrm{wt} \%$ nominal carbon loss per cycle. It shall be noted that the average and standard deviations (error bars) were evaluated based on all relevant measurements (i.e. BOL-characterizations were averaged on all 12 MEAs; Cyc 1-3 were averaged on MEA No. 1-6; Сус 4 on No. 3-6 and Cyc 5 on No. 5-6, refer to Table 1). This averaging is also applied for Figs. 3-5.

Unsurprisingly, the performance decreases monotonically with increasing amount of corrosion cycles. The performance losses seem relatively proportional to the number of cycles for the first 


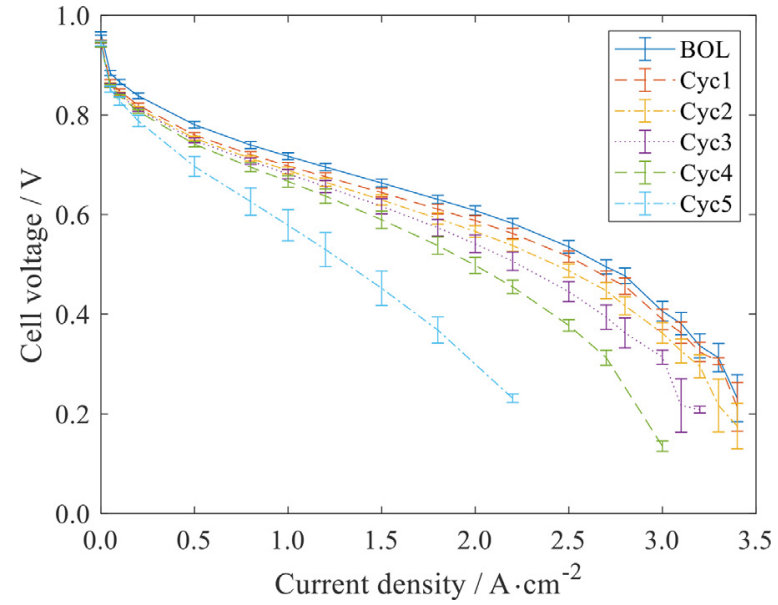

Fig. 2. Polarization curves at beginning-of-life (BOL) and after various number of corrosion cycles (1-5). Each corrosion cycle corresponds to $8 \mathrm{wt} \%$ nominal carbon loss based on the pre-test using pure carbon cathodes (see details in Experimental section or discussions in the Supplementary Material). All curves were measured under $80^{\circ} \mathrm{C}, 90 \% \mathrm{RH}, 170 \mathrm{kPa}$ (absolute) back pressure under $\mathrm{H}_{2}$ /air differential flows $\left(1.0 / 2.0 \mathrm{NL} \mathrm{min}^{-1}\right)$.

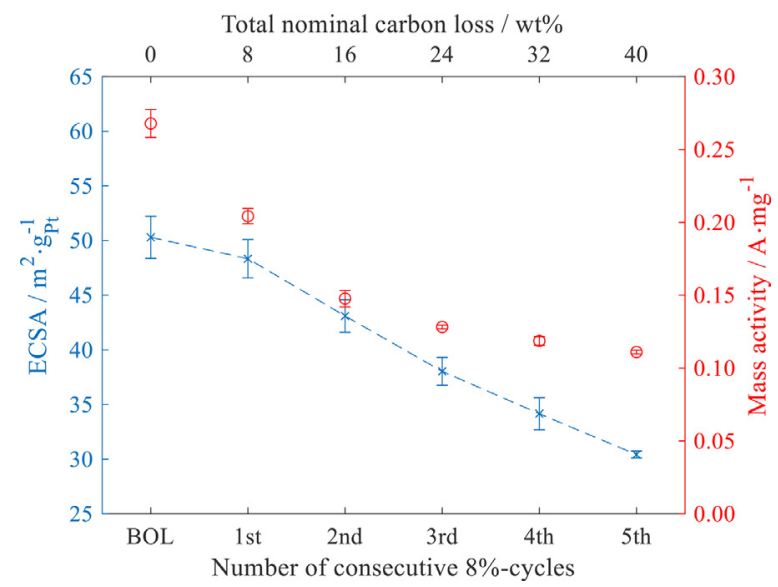

Fig. 3. Electrochemical active surface area (ECSA, blue left axis) and mass activity (red right axis) of the MEA at BOL and after 1-5 corrosion cycles. Each corrosion cycle corresponds to $8 \mathrm{wt} \%$ nominal carbon loss based on the pre-test using pure carbon cathodes. The ECSAs were determined via CO stripping method at $80^{\circ} \mathrm{C}$ and $90 \% \mathrm{RH}$, whereas the mass activity was evaluated from $\mathrm{H}_{2} / \mathrm{O}_{2}$ polarization curves at $80^{\circ} \mathrm{C}$ and $100 \% \mathrm{RH}$.

3-4 corrosion cycles (i.e. around 30\% total carbon loss), before becoming over-proportional for the final cycle. At this stage, it could be speculated that carbon corrosion has induced two main mechanisms of extra voltage losses (a possibility being kinetic losses and $\mathrm{O}_{2}$ mass transport losses), where one is close to proportional to carbon loss, and the other is over-proportional and starts dominating at a carbon loss threshold of around 30wt\%. To gain a deeper understanding on these mechanisms of performance losses, the individual known types of the voltage losses (kinetic, ohmic and mass transport) will be examined in the following sections.

\subsection{Kinetic losses}

The increase in kinetic voltage losses induced by carbon corrosion is reflected by the changes of ECSA and the mass activity of the MEA, shown in Fig. 3. Evidently, the ECSA losses are nearly proportional to the carbon loss under the given test sequence. During carbon corrosion at the cathode $\mathrm{CL}$, several mechanisms may lead to a loss of ECSA. On the first hand, corrosion of the carbon support causes a physical detachment of Pt nanopar-

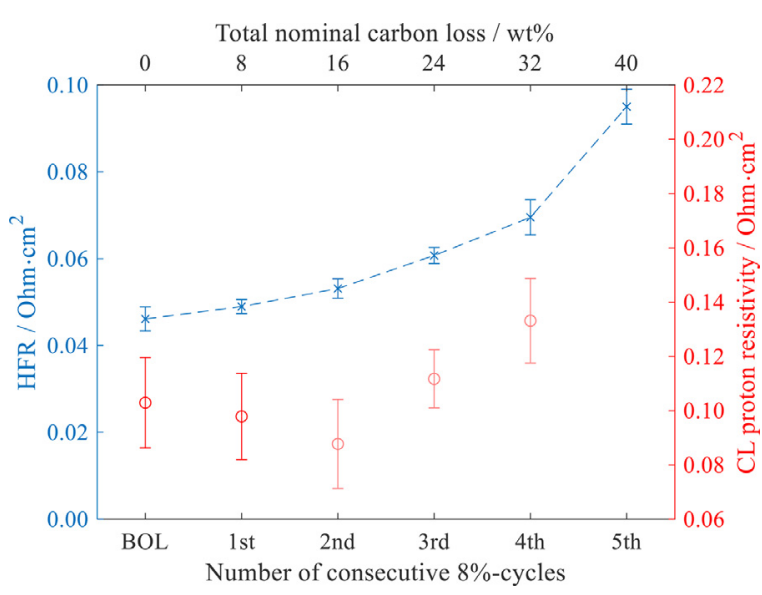

Fig. 4. High frequency resistance (HFR, blue left axis) of the MEA and protonic resistivity (in $\Omega \cdot \mathrm{cm}^{2}$, red right axis) of the cathode CL at BOL and after 1-5 corrosion cycles. Each corrosion cycle corresponds to $8 \mathrm{wt} \%$ nominal carbon loss based on the pre-test using pure carbon cathodes. The protonic resistivities were determined from $\mathrm{H}_{2} / \mathrm{N}_{2}$ EIS spectra which were obtained at $80^{\circ} \mathrm{C}$ and $90 \% \mathrm{RH}$. The lighter color from the second cycle onwards indicates higher uncertainties in determining the proton resistivities.

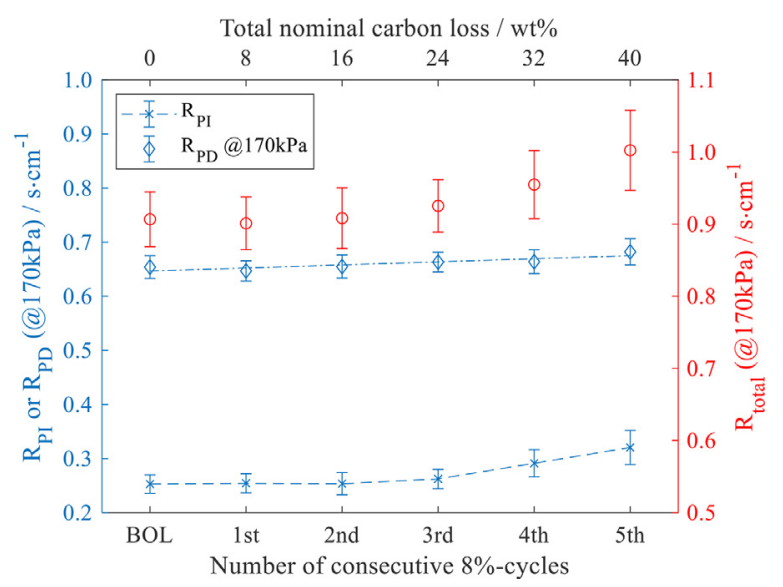

Fig. 5. Total oxygen transport resistance $\left(R_{\text {total }}\right)$ at $170 \mathrm{kPa}$ (red right axis) and its deconvolution into pressure dependent $\left(R_{\mathrm{PD}}\right)$ or independent $\left(R_{\mathrm{PI}}\right)$ terms (blue left axis) at BOL as well as after 1-5 corrosion cycles. Each corrosion cycle corresponds to $8 \mathrm{wt} \%$ nominal carbon loss based on the pre-test using pure carbon cathodes. $R_{\text {total }}$ was obtained from limiting current measurements utilizing $4 \% \mathrm{O}_{2}$ at $80^{\circ} \mathrm{C}$ and $90 \% \mathrm{RH}$.

ticles from the carbon, rendering them electrochemically inactive [19-22]. Additionally, repetitive oxidation and reduction of the Pt surface (e.g. during the different characterization steps) will lead to dissolution of $\mathrm{Pt}$ ions in the ionomer phase [23,54,55]. Some of these Pt ions will migrate into the membrane and ultimately get reduced there as a result of the $\mathrm{H}_{2}$ crossover, leaving electrochemically inactive Pt particles in the form of Pt band, as it is also visible from the postmortem analysis (see Fig. 8a). Another mechanisms involves Ostwald-ripening, where the Pt ions are preferably redeposited onto larger particles $[19,21,56]$. It shall be noted here, however, that a deconvolution of obtained ECSA loss into various Pt loss mechanisms (e.g. shown by Sharma et al. [24]) is not possible via the experimental procedure introduced in the present study (CO stripping, postmortem using SEM).

The trend of ECSA losses agrees reasonably well with Hashimasa et al.'s results [34], where a nearly linear correlation may be found between ECSA loss and the amount of carbon loss (refer to Fig. 1 of the mentioned publication) under all three applied AST protocols. Nonetheless, Hashimasa et al. showed more significant ECSA losses compared to the present study, where un- 
der the USFCC/DOE protocol (hold at $1.2 \mathrm{~V}$ for $15 \mathrm{~h} / 24 \mathrm{~h}$ per cycle, respectively; compared to hold at $1.4 \mathrm{~V}$ in the present study), around $25 \mathrm{wt} \%$ carbon was lost after $30 \mathrm{~h}$ which had induced around 40 $\%$ ECSA losses. This quantitative difference may be caused by the different carbon type on the cathode (EC300J vs. TEC10E50E), the difference in carbon corrosion cycle, as well as the characterization protocols (refer to the discussions in Section 4.6).

ECSA losses during carbon corrosion were also reported in other published work $[21,24,35,57]$. However, the ECSA values were generally correlated with the number of AST cycles without information on the carbon loss, making the comparison of the results with the present study very challenging.

On the other hand, Pt mass activity drops more significantly during the first cycles of carbon corrosion, before getting stable at around $0.12 \mathrm{~A} \mathrm{mg}^{-1}$ (around 50\% decrease from BOL). This agrees very well with the polarization curves shown in Fig. 2, where it can be observed that under low current densities $\left(<0.5 \mathrm{~A} \mathrm{~cm}^{-2}\right)$, the drop of polarization performance from BOL to the first cycle is more significant than the decrease during the following three cycles. The significant extra voltage losses at cycle 5 that may be observed in Fig. 2 shall, on the other hand, be explained by the considerable increase in ohmic losses (see Section 4.3). As extra confirmation, Fig. S8 depicts HFR-corrected polarization curves, where it can be observed that the corrected cell voltage is very similar for cycle 3-5.

This initial stronger decrease of mass activities was also observed elsewhere [27] and could be attributed to the opening of carbon porous structure and exposing of internal Pt particles to the ionomer (note that $70 \%$ of the Pt particles were originally located within the carbon primary pores, see Experimental). When Pt is in contact with the ionomer, it is well-known that ionomer sulfonic groups adsorb onto the Pt particle and exert a poisoning effect, leading to an overall reduction of mass activity $[11,47,58]$. Furthermore, a part of this mass activity loss may also be attributed to the growth of Pt particles which is induced by carbon corrosion [24].

\subsection{Ohmic losses}

Typically, ohmic losses within the MEA are associated with high-frequency resistances (HFRs) and the protonic resistance of the cathode catalyst layer. These values alongside with their observed change during the course of carbon corrosion are illustrated in Fig. 4.

The HFRs show a clear increasing trend with respect to corrosion cycles. This is likely caused by increasing electrical contact resistance between the GDL and the cathode $\mathrm{CL}$, as a result of cathode electrode thinning and reduction of GDL compression [25]. This reduction in GDL compression might additionally lead to increased contact resistance between the GDL and the bipolar plate (BPP). Furthermore, loss in (protonic) contact between the cathode $\mathrm{CL}$ and the membrane has been proposed $[23,26]$.

The proton resistivity of the cathode CL decreases during the first few corrosion cycles. This is expected since the ionomer volume fraction in the CL increases as carbon volume decreases. Similar trend at beginning of corrosion was also observed by other studies $[20,26]$. On the other hand, the proton resistivity seems to start increasing from a certain threshold of carbon loss, indicating possible damage to the protonic conductive pathway within the cathode. This agrees with the observations in the literature $[26,35]$. Nonetheless, it shall be noted that the CL proton resistivities shown in Fig. 4 have relatively high uncertainties, especially after increased number of corrosion cycles (lighter red colors in the graph). This is related to the respective $\mathrm{H}_{2} / \mathrm{N}_{2}$ spectra, where the high-frequency branch deviates increasingly strongly from the theoretical $45^{\circ}$ line during the course of carbon corrosion, leaving the fitting procedure more challenging and creating more errors (refer to Fig. S3). Additionally, no reliable protonic resistance may be extracted from the EIS spectrum after 5 corrosion cycles (this point is therefore absent in Fig. 4), where the high-frequency branch was nearly flat. A more detailed discussion on the $\mathrm{H}_{2} / \mathrm{N}_{2}$ spectra are given in the Supplementary Material (Fig. S3).

\subsection{Mass transport losses}

To investigate the contribution of mass transport resistance on the MEA performance loss after carbon corrosion, total oxygen mass transport resistances $\left(R_{\text {total }}\right)$ were obtained using the limiting current method. The deconvolution of $R_{\text {total }}$ into its pressure dependent $\left(R_{\mathrm{PD}}\right)$ and independent terms $\left(R_{\mathrm{PI}}\right)$ was performed according to Baker et al. [50], by conducting the limiting current measurement under various total pressures $(170,230$ and $300 \mathrm{kPa})$.

As shown in Fig. $5, R_{\mathrm{PD}}$ is hardly influenced by the carbon corrosion (variations within error bars). This is not surprising since $R_{\mathrm{PD}}$ mainly consists of $\mathrm{O}_{2}$ mass transport resistances within the GDL and the flow field channel, where these two fuel cell components are not expected to be influenced by carbon corrosion. On the other hand, $R_{\mathrm{PI}}$ shows a clear increasing trend starting from the third corrosion cycle. It is well known that the $R_{\mathrm{PI}}$ comprises Knudsen diffusion within the $\mathrm{CL}$ porous region $\left(R_{\mathrm{PI}, \mathrm{Kn}}\right)$ and $\mathrm{O}_{2}$ transport through the Pt/ionomer interface $\left(R_{\mathrm{Pt} / \text { ion }}\right)$ [59], as shown in Eq. (4). Therefore, the increase in $R_{\mathrm{PI}}$ starting from the third cycle shall be explained by a combination of cathode porosity loss (see Table 4, increase of $R_{\mathrm{PI}, \mathrm{Kn}}$ ) and loss of ECSA (reduction of the fraction $R_{\mathrm{Pt} / \text { ion }}$ $(r f)$.

$R_{\mathrm{PI}}=R_{\mathrm{PI}, \mathrm{Kn}}+\frac{R_{\mathrm{Pt} / \mathrm{ion}}}{r f}$

The increase of $R_{\mathrm{PI}}$ of around $30 \%$ after 5 corrosion cycles (which would correspond to a total of $40 \mathrm{wt} \%$ carbon loss and around 40\% ECSA loss) may seem relatively insignificant. However, the damage to the cathode in the present study, even at $40 \%$ carbon loss, was also still relatively small compared to a number of durability studies $[8,15,34]$. It shall be noted that in our case, the cathode still shows sufficient porosity even at $40 \%$ carbon loss (refer to Fig. 8 for the SEM micrograph) and hence will not strongly hinder Knudsen diffusion. In addition, cathode flooding (which reduces effective porosity) is highly unlikely under limiting current conditions $\left(4 \% \mathrm{O}_{2}\right)$ due to the relatively low current density $(<0.8$ $\mathrm{Acm}^{-2}$ ). Regarding the correlation between $R_{\mathrm{PI}}$ increase and ECSA loss, a comparison can be given with Harzer et al. [8] who showed around $80 \%$ ECSA loss after 10,000 potential cycles of triangle wave (without carbon corrosion), while $R_{\mathrm{PI}}$ only increased for around 20 $\%$.

For a deeper understanding on the mass transport related losses, $R_{\text {PI }}$ shall be deconvoluted according to Eq. (4) [59]. As none of the three variables on the right side of Eq. (4) is expected to remain constant during the carbon corrosion test, a simple plot of $R_{\mathrm{PI}}$ against $r f$ will not provide useful information. Nor would the methodology of varying Pt loadings apply in the present case due to its inevitable "invasiveness" on the carbon corrosion experiment.

To obtain a reasonable estimation of $R_{\mathrm{Pt} / \text { ion }}$ despite the abovementioned difficulties, the 1D polarization model (see Section 3 ) is applied under limiting current conditions (i.e. $4 \% \mathrm{O}_{2}$ ). As all other inputs for the model were obtained during the in situ characterizations (see also Tables 2 and S3), $R_{\mathrm{Pt} \text { /ion }}$ could be varied until the limiting current predicted by the model agrees with the experimental observation. An example of this procedure is shown in Fig. S6. It should be mentioned that although the simplified model does not account for water transport, very little water amount is expected to be produced under diluted oxygen conditions due to the small current densities. 
Table 2

Parameters used in the 1D model at beginning-of-life (BOL) and after three corrosion cycles with $8 \mathrm{wt} \%$ nominal carbon loss per cycle. Besides the Pt/ionomer interfacial resistance, all parameter values were determined experimentally (refer to Section 4.7 for the determination of CL thickness and Table S6 for the estimation of porosity).

\begin{tabular}{lll}
\hline Parameter (in situ characteristics) & $\mathrm{BOL}$ & $8 \% \times 3$ \\
\hline Pt loading $/ \mathrm{mg}_{\mathrm{Pt}} \mathrm{cm}^{-2}$ & 0.33 & \\
$\mathrm{ECSA} / \mathrm{m}^{2} \mathrm{~g}_{\mathrm{Pt}}{ }^{-1}$ & 50.3 & 38.0 \\
Mass activity (MA) / $\mathrm{A} \mathrm{mg}_{\mathrm{Pt}}{ }^{-1}$ & 0.268 & 0.128 \\
$\mathrm{HFR} / \Omega \mathrm{cm}^{2}$ & 0.046 & 0.061 \\
$\mathrm{CL}$ protonic resistivity $\left(R_{\mathrm{ca}, \mathrm{H}+}\right) / \Omega \mathrm{cm}^{2}$ & 0.103 & 0.112 \\
Pt $/$ ionomer interfacial resistance $\left(R_{\mathrm{Pt} / \mathrm{ion}}\right) / \mathrm{s} \mathrm{cm}^{-1}$ & 20.1 & 17.6 \\
$R_{\mathrm{PD}}$ at $170 \mathrm{kPa}$ total pressure $/ \mathrm{s} \mathrm{cm}^{-1}$ & 0.654 & 0.663 \\
$\mathrm{CL}$ porosity $(\varepsilon)$ & 0.57 & 0.58 \\
$\mathrm{CL}$ thickness $/ \mu \mathrm{m}$ & 7.2 & 6.5 \\
$\mathrm{H}_{2}$ crossover $\left(i_{\mathrm{x}}\right) / \mathrm{mAcm}^{-2}$ & 8.9 & 8.3 \\
\hline
\end{tabular}

Utilizing this methodology, a BOL value of $20.1 \pm 2.7 \mathrm{~s} \mathrm{~cm}^{-1}$ is yielded for $R_{\mathrm{Pt} / \mathrm{ion}}$, which is within reasonable range compared to values reported by the literature $[30,60]$. Values for later stages during the carbon corrosion experiment are reported in the Supplementary Material (see also Fig. S7).

\subsection{Reconstruction of polarization curves from in situ characteristics}

With the in situ electrochemical properties of the MEA characterized at various stages of the corrosion, these data are utilized to recreate the polarization curves using the developed 1D model (refer to Section 3 for the modeling details), where the results are compared with the empirically obtained curves. This approach serves to find out whether the different loss terms can be combined to explain the observed voltage losses in the polarization curve. For MEAs at BOL and after three corrosion cycles of $8 \mathrm{wt} \%$ carbon loss, the necessary parameter inputs are listed in Table 2. It shall be emphasized that all values (except for $R_{\mathrm{Pt} / \text { ion }}$, see discussions in the previous paragraph) were obtained purely experimentally.

The comparison between this recreated and the experimentally obtained polarization curves is depicted in Fig. 6a. Evidently, both at BOL and after three cycles, the predicted polarization performances agree very well with the experimental values up to a current density of around $2.2 \mathrm{~A} \mathrm{~cm}^{-2}$. This suggests that within this current density range, all voltage losses to the MEA (including the additional losses due to the carbon corrosion) are very accurately represented by the measured electrochemical characteristics. At the same time, this agreement suggests that the simplified 1D model performs well in predicting the cell performance even without the implementation of water-related phenomena.

As an additional confirmation, a "OD" polarization curve calculation as reported by Orfanidi et al. [45] is performed, applying the same parameter inputs in Table 2. Fig. 6b,c depicts the difference of both reconstructed polarization curves to the experimental ones at BOL or after three corrosion cycles. Evidently, also the OD approach yields good agreement for a wide range of current densities, verifying the accuracy of the model and the in situ measurements. While both $0 \mathrm{D}$ and $1 \mathrm{D}$ calculations match very well at low current densities $\left(<1 \mathrm{~A} \mathrm{~cm}^{-2}\right)$, it can be observed that the 1D model mimics the experimental results more precisely at medium/high current densities, especially at around $2 \mathrm{~A} \mathrm{~cm}^{-2}$. The shortcoming of the $0 \mathrm{D}$ calculation shall be attributed to its over-simplification, where effects such as CL proton resistivity are taken into account via effective transport properties [45]. It shall be additionally noted that the $0 \mathrm{D} / 1 \mathrm{D}$ approach in the present study gives by far better results than what was reported by Harzer et al. [8], especially by considering that a very similar experimental protocol and Pt loading $\left(0.4 \mathrm{mg} \mathrm{cm}^{-2}\right)$ was used in both studies. The unaccounted loss in Harzer et al. amounts to $40-60 \mathrm{mV}$ at $2 \mathrm{~A} \mathrm{~cm}^{-2}$ after degradation (and up to $>200 \mathrm{mV}$ in some cases), where its origin could not be identified. In our case, the deviation is only around $10 \mathrm{mV}$ with the 1D calculation after three corrosion cycles.

While the $1 \mathrm{D}$ model in the present study yields better results than the $\mathrm{OD}$ calculation in the literature at high current densities, neither approach sufficiently reproduces the mass transport region $\left(>2.5 \mathrm{~A} \mathrm{~cm}^{-2}\right)$ of the polarization curve. To explain this discrepancy, it shall be first noted that the model was "calibrated" (by varying $R_{\mathrm{Pt} / \text { ion }}$ ) to the limiting current measurement conditions (see discussions in Section 4.4). Therefore, the difference is very likely caused by liquid water, a factor that is absent or insignificant during limiting current measurements. Since the simplified model account for neither water transport nor liquid water related phenomena, the "effective" porosity within the CL may be significantly overestimated due to the CL flooding and the pore blockage under high current densities. This further leads to an underestimation of the Knudsen diffusion part of the total resistance $\left(R_{\mathrm{Kn}}\right)$ within the mass transport region. The fact that the discrepancy of polarization curves at $>2 \mathrm{~A} \mathrm{~cm}^{-2}$ is more significant after carbon corrosion (compare Fig. 6c to b) could possibly be explained by the decrease of cathode hydrophobicity [27] and thus the more severe flooding under high current outputs. At this point, we would like to notice that an extension of the simplified model to account for the liquid water effect would additionally require detailed empirical information, e.g. related to the change of capillary force relationships within the electrode. This would represent a viable research direction for further carbon corrosion studies.

It remains to be mentioned that the accuracy of the abovementioned voltage loss analysis is further supported by the reconstruction of polarization curves for the MEA after 4 corrosion cycles. The comparison is shown in the Supplementary Material (refer to Fig. S9 and Table S3). However, the reconstruction for the MEA after 5 cycles is infeasible due to the very high uncertainty of the proton resistivity (see discussions in Section 4.3).

\subsection{Invasiveness of characterization steps during carbon corrosion experiment}

It is widely known in the literature that voltage cycling leads to Pt dissolution and ECSA losses [24,38,61]. The characterization steps within the present test protocol introduce the variation of cathode potential between the limiting current range (i.e. $0.2 \mathrm{~V}$ vs. RHE) and the carbon corrosion potential (1.4V vs. RHE). This section aims to investigate the influence of this "voltage variations" on the results of the carbon corrosion experiment. For this purpose, we direct our attentions towards the test sequence with a single corrosion cycle applied (refer to MEA No. 7-12 in Table 1), where the nominal carbon loss is equivalent to the multiple cycles presented before. It shall be mentioned that the duration of the single corrosion cycles was again determined via the pre-test using pure carbon cathode (see discussions in the Supplementary Material, section "Current responses during corrosion cycles on pure carbon and Pt/C cathodes").

Fig. 7a compares the ECSA losses between these two test sequences. The ECSA has decreased considerably more strongly in all cases of multiple cycles, despite the similar amount of total carbon loss compared to the single corrosion cycle. At a nominal carbon loss of $40 \mathrm{wt} \%$, the single cycle has induced an ECSA loss of $<20$ $\%$, whereas five $8 \%$-cycles have led to more than double the ECSA losses (around 40\%). The major difference between the two test sequences is the number of characterization blocks, which scales directly with the number of corrosion cycles (after every corrosion cycle, a characterization block was conducted, refer to Fig. 1a). Therefore, it is highly likely that the differences observed in the ECSA losses have resulted from the characterization steps, which 
a)
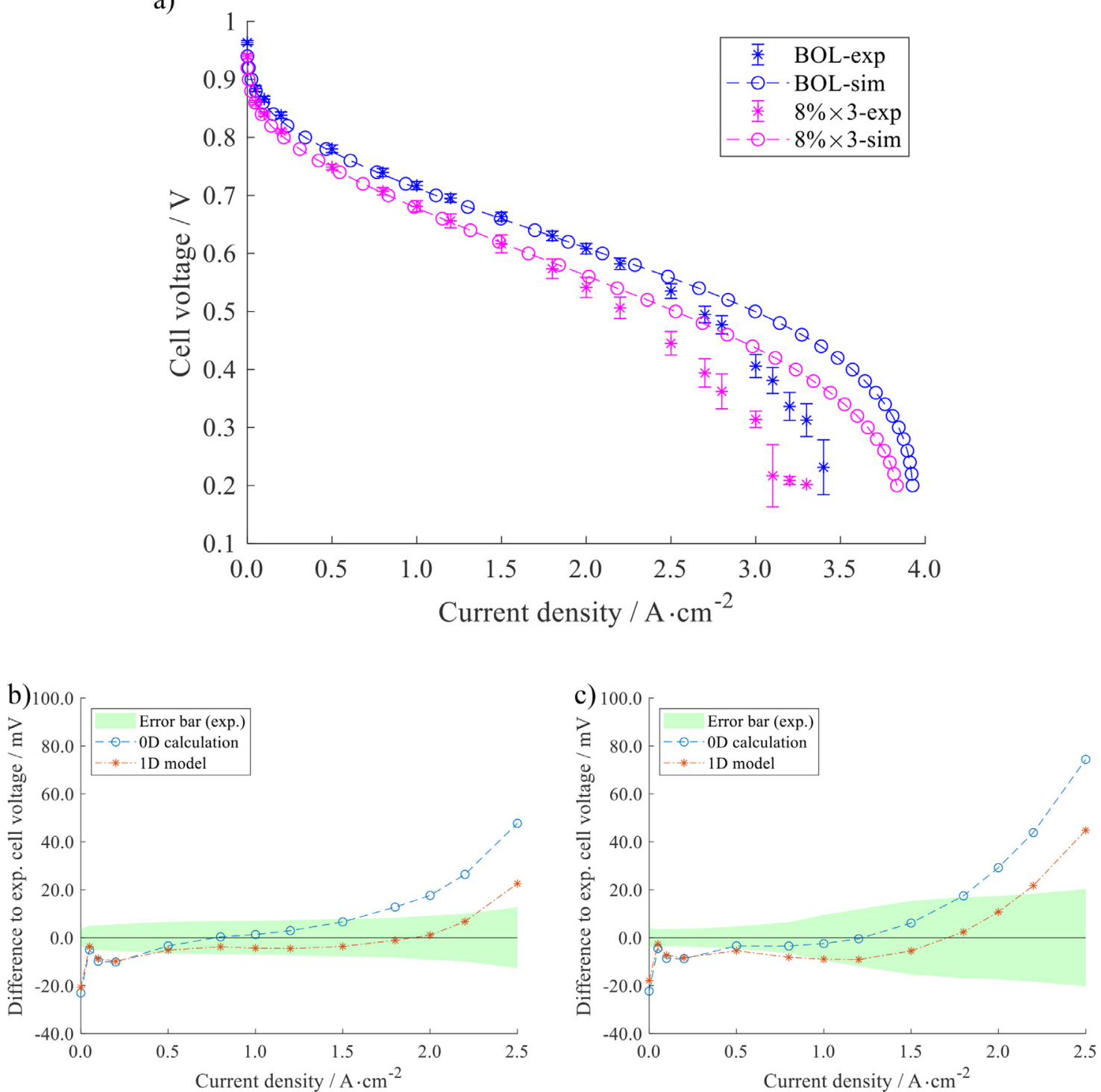

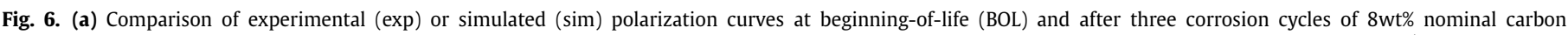

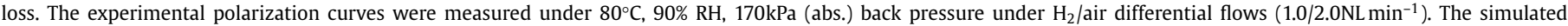

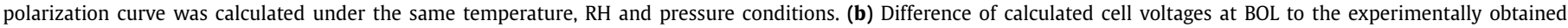

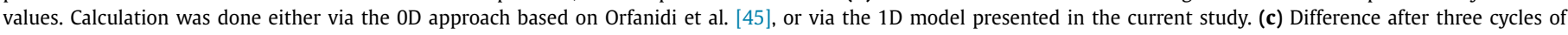
$8 \mathrm{wt} \%$ carbon loss.

include MEA operations under very low cell voltage (e.g. $0.2 \mathrm{~V}$ for the limiting current; $>3 \mathrm{~A} \mathrm{~cm}^{-2}$ points in the polarization curve; $<$ $0.1 \mathrm{~V}$ during the $\mathrm{CV}$ ). Very similar concept of this "observational potential cycling" was also demonstrated in the literature for carbon corrosion related degradations [21]. On one hand, the exposing to low potentials will remove any passivation layer of Pt oxide during the previous corrosion stage and may lead to more dissolution during later stages [42]; on the other hand, dissolved Pt ions will be redeposited, where the harsh reduction environment likely results in electronic isolated (thus inactive) Pt particles and increasing of particle sizes. It shall be emphasized that with the current experimental setup, a couple of cycles (3-5) have already led to a considerable increase in ECSA losses, whereas in voltage cycling studies, thousands of cycles are typically needed to reach similar losses [62]. This may be an indication that carbon corrosion and subsequent voltage cycling has some synergetic effects on ECSA losses. A possible explanation for this is that the contact between the Pt particles and the carbon support is weakened during carbon corro- sion, increasing the possibility of Pt movement which will lead to higher chances of agglomeration or detachment.

Table 3 additionally compares other in situ electrochemical characteristics between the two test sequences. Evidently, neither HFR nor the $\mathrm{O}_{2}$ transport resistance is affected by the number of cycles (characterization steps). It is not unexpected that the HFR depends exclusively on the total extent of carbon loss, since it only increases due to the additional contact resistances within the MEA. On the other hand, it is intriguing that $R_{\mathrm{PI}}$ seems not to be influenced by the characterization steps in spite of the differences in the ECSA (note the dependence of $R_{\mathrm{PI}}$ on $r f$ according to Eq. (4)). This may indicate that the additional characterizations have exerted some influences on the Pt/ionomer interface (change of $R_{\mathrm{Pt} / \text { ion }}$ to counteract change of $r f$ ), which may be due to ionomer displacement/movement during the carbon corrosion within the $\mathrm{CL}$. The difference in CL protonic resistivity between the $8 \% \times 4$ and the $32 \% \times 1$ case (refer to Table 1 for the nomenclature) seems to support this proposition, as it could be an indication that the 
Table 3

Comparison of in situ electrochemical characteristics that is related to ohmic/mass transport losses during single or multiple corrosion cycles.

\begin{tabular}{llll}
\hline In situ characteristics & $8 \% \times 3$ & $24 \% \times 1$ & $8 \% \times 4$ \\
\hline HFR $/ \Omega \mathrm{cm}^{2}$ & $0.061 \pm 0.002$ & $0.062 \pm 0.001$ & $0.070 \pm 0.004$ \\
CL protonic resistivity / $\Omega \mathrm{cm}^{2}$ & $0.112 \pm 0.011$ & $0.110 \pm 0.007$ & $0.133 \pm 0.016$ \\
$R_{\mathrm{PD}} @ 170 \mathrm{kPa} / \mathrm{s} \mathrm{cm}^{-1}$ & $0.663 \pm 0.019$ & $0.674 \pm 0.030$ & $0.064 \pm 0.022$ \\
$R_{\mathrm{PI}} / \mathrm{s} \mathrm{cm}^{-1}$ & $0.262 \pm 0.018$ & $0.252 \pm 0.006$ & 0.006 \\
\hline
\end{tabular}
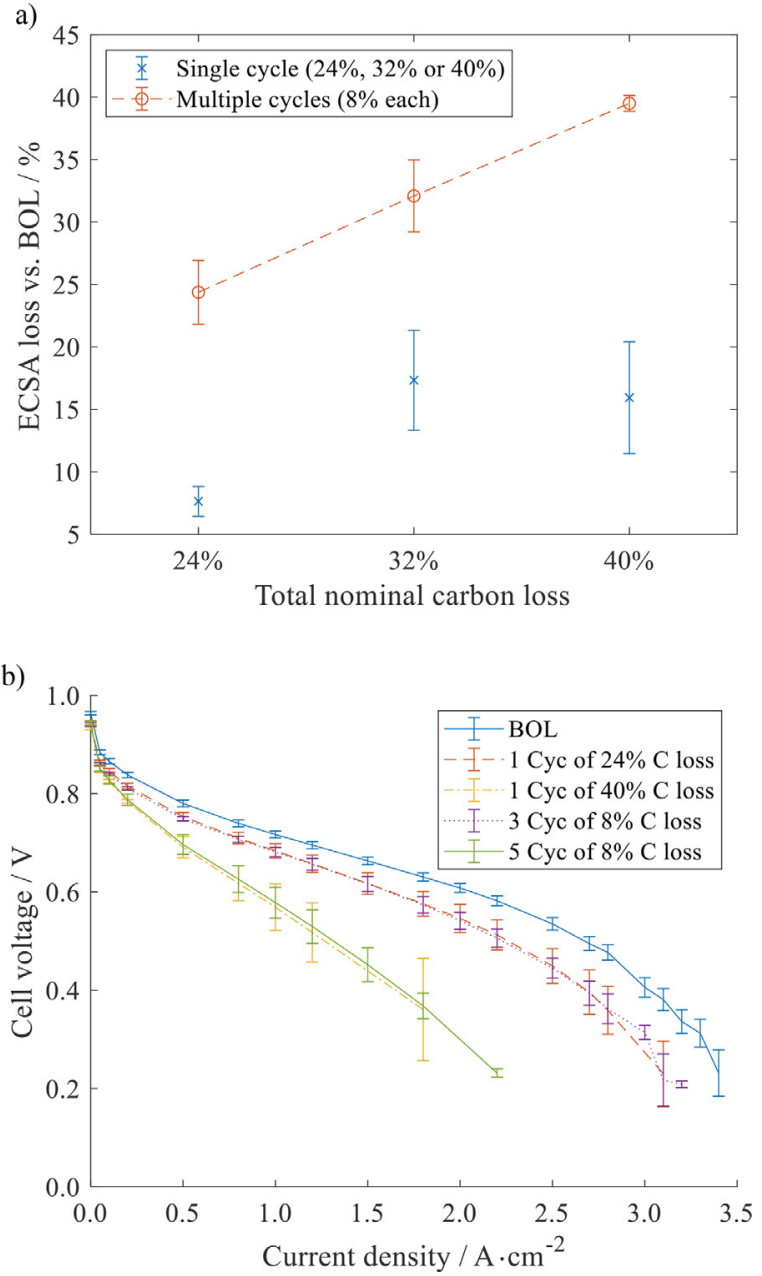

Fig. 7. (a) Comparison of ECSA loss (normalized to BOL value) for the MEA after 3-5 cycles of $8 w t \%$ nominal carbon loss $(8 \% \times 3,8 \% \times 4,8 \% \times 5)$, or after a single corrosion cycle of 24,32 , or 40 wt $\%$ carbon loss $(24 \% \times 1,32 \% \times 1,40 \% \times 1)$. (b) Polarization curves measured at BOL, $8 \% \times 3,8 \% \times 5,24 \% \times 1$ and $40 \% \times 1$.

"invasiveness" of characterization steps also includes distortion of proton conductive pathway.

Fig. $7 \mathrm{~b}$ additionally illustrates the polarization curves at BOL, after 3 or 5 cycles of $8 \mathrm{wt} \%$ carbon loss $(8 \% \times 3,8 \% \times 5)$, as well as after a single corrosion cycle with $24 \mathrm{wt} \%$ or $40 \mathrm{wt} \%$ carbon loss $(24 \% \times 1,40 \% \times 1)$. Evidently, no significant differences in polarization performances are found between these two different test sequences. Additionally, the simulative reconstruction of the polarization curves (similar to Fig. 6) is performed for the $24 \mathrm{wt} \%$ and 32 wt\% cycle (details see Fig. S11), confirming that most of the voltage losses can be represented by the in situ characteristics. The relatively low sensitivity of the ECSA on the polarization performance is very likely due to the high Pt loading of the MEAs $(0.326$ $\mathrm{mg}_{\mathrm{Pt}} \mathrm{cm}^{-2}$ ).

\subsection{Postmortem analyses}

Fig. 8 depicts SEM images of the CCM cross-section after five corrosion cycles (40wt\% carbon loss in total). Significant Pt band formation within the membrane is observed, where a qualitative confirmation of Pt element via EDX is shown in Fig. S13. The formation of Pt particles can be observed within the membrane in the zoomed-in micrograph (Fig. 8b). The Pt migration indicates considerable Pt detachment from the cathode during the corrosion course which has contributed to the ECSA losses observed in Fig. 3. It shall be noted that the SEM micrographs do not allow a quantification of Pt migration into the membrane. Nor would the EDX analysis provide sufficiently accurate quantitative information in this regard, as both $\mathrm{C}$ and Pt are lost from the cathode simultaneously.

Nevertheless, qualitative differences can be observed in dependence of the testing protocol. More specifically, Fig. 9 shows a similar SEM micrograph of the MEA after a single corrosion cycle of 40 wt\% nominal carbon loss. While some Pt particles can still be observed in the membrane, the formed Pt band is considerably less significant compared to Fig. 8a, considering their very similar resolutions. This observation agrees well with the trend of ECSA shown in Fig. 7b, confirming that the application of more corrosion cycles (despite similar total corrosion amount) led to more Pt dissolution and ECSA loss from the cathode.

On the other hand, it is evident from the micrographs that even after around $40 \%$ carbon loss (either $40 \% \times 1$ or $8 \% \times 5$ ), the cathode remains relatively porous. A quantitative determination of the porosity, however, is not possible from these graphs due to their limited contrast, where the interfaces between the pores and carbon particles cannot be exactly defined. An estimation of the porosity values is given in the Supplementary Material (see Eq. (S15) and Table S5-S6). Representative images of the cross-section from the samples (obtained via light microscope) are shown in Fig. S14. Based on the electrode thicknesses presented in Table 4, it is clear that there exists no trend nor clear dependency of the corrosion protocol (single or multiple cycles) with respect to the electrode thinning. As also mentioned previously, this is not entirely surprising as the electrode thickness is expected to be well correlated with the overall carbon loss which are very similar in both test sequences.

It remains to be mentioned that the estimated porosity after 24 wt\% of carbon loss (either $24 \% \times 1$ or $8 \% \times 3$ ) is very similar to that at BOL. This serves as an indication that some structural collapse of the cathode only took place after around 30wt\% of carbon has been lost. This agrees well with the observations by Fang et al. [27], who reported nearly constant (with initial slight increase) CL porosity up to the carbon loss of around $35 \mathrm{wt} \%$.

\section{Conclusion}

Corrosion of carbon as catalyst support within PEMFCs is known to induce performance losses, typically explained by changes in MEA characteristics such as decreasing ECSA and increasing mass transport resistances. In the present study, extensive in situ electrochemical characterizations were conducted during a carbon corrosion protocol with multiple corrosion cycles under po- 
a)

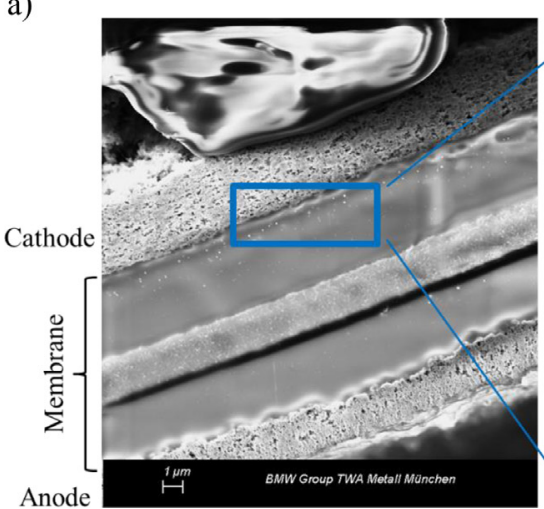

b)

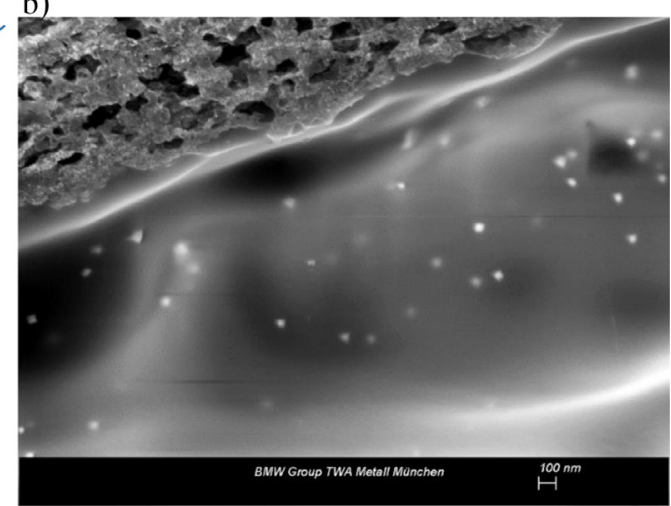

Fig. 8. (a) SEM micrograph of MEA after five corrosion cycles with 8wt\% nominal carbon loss per cycle. Cathode on the top side. (b) is a localized zoomed-in version of (a).

Table 4

Cathode thickness obtained from MEA postmortem analysis. The average value and standard deviation of the thicknesses represent the thickness variation between different measurement points of the cathode CL within one cross-section.

\begin{tabular}{ll}
\hline MEA State & Thickness / $\mu \mathrm{m}$ \\
\hline Pristine, beginning-of-life (BOL) & $7.3 \pm 0.7$ \\
$8 \% \times 3$ (after three corrosion cycles with 8wt\% nominal carbon loss each) & $6.5 \pm 0.5$ \\
$8 \% \times 4$ & $4.3 \pm 0.5$ \\
$8 \% \times 5$ & $4.6 \pm 0.4$ \\
$24 \% \times 1$ (after single corrosion cycle with 24wt\% nominal carbon loss) & $6.3 \pm 0.5$ \\
$32 \% \times 1$ & $5.3 \pm 0.3$ \\
$40 \% \times 1$ & $3.6 \pm 0.1$ \\
\hline
\end{tabular}

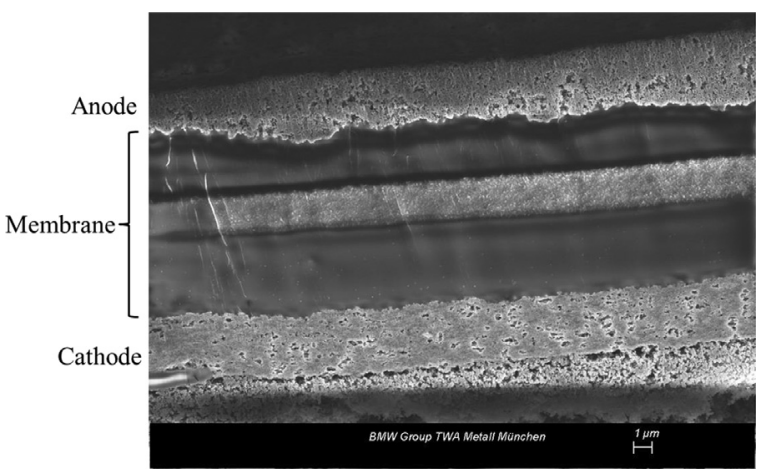

Fig. 9. SEM micrograph of MEA after one corrosion cycle with 40wt\% nominal carbon loss. Cathode on the bottom side.

tential holding at $1.4 \mathrm{~V}$ vs. RHE. By developing a one-dimensional model that utilizes the empirical characteristics as parameter inputs, the MEA polarization curves can be reconstructed at various stages of the applied corrosion procedure. A comparison with the in situ obtained polarization performance yields a good agreement up to a current density of around $2.2 \mathrm{~A} \mathrm{~cm}^{-2}$, indicating that nearly all the voltage losses can be accurately captured by the characterized loss terms. The quality of this reconstruction is further confirmed via a "OD" voltage loss analysis reported in the literature, using the same parameter set. The 1D model is shown to match with the experimental data very well at medium/high current densities even without the implementation of water-related phenomena.

By comparing MEA characteristics after carbon corrosion protocols with different numbers of corrosion cycles, it is additionally found that the application of characterization steps has introduced significant adverse "observer effects" on the ECSA, despite having the same amount of carbon loss. This is presumably caused by the "voltage cycling" conditions due to the switch between the corrosion protocol at $1.4 \mathrm{~V}$ and the characterization steps with as low as $0.2 \mathrm{~V}$ cell voltage. The increased Pt loss induced by multiple characterization steps is further confirmed by SEM postmortem analysis, where an increased significance of Pt band within the membrane can be observed. Based on these observations, the authors note that the famous motto "the more information obtained, the better" does not always apply in the case of in situ characterizations during carbon corrosion experiment, where the necessity of certain characterization steps (especially these that would introduce strong reducing environment e.g. limiting current, which would adversely influence the ECSA) should be thought thoroughly prior to any experiments.

\section{Declaration of Competing Interest}

The authors declare that they have no known competing financial interests or personal relationships that could have appeared to influence the work reported in this paper.

\section{Credit authorship contribution statement}

Fengmin Du: Conceptualization, Methodology, Software, Validation, Data curation, Formal analysis, Investigation, Writing - original draft, Writing - review \& editing, Visualization. Tuan Anh Dao: Methodology, Software, Formal analysis, Writing - review \& editing. Andreas Bauer: Formal analysis, Investigation, Resources, Data curation, Writing - review \& editing. Michael Obermaier: Investigation, Resources, Writing - review \& editing. Thomas J. Schmidt: Conceptualization, Methodology, Writing - review \& editing, Supervision. Alin Orfanidi: Conceptualization, Methodology, Data curation, Formal analysis, Writing - original draft, Writing - review \& editing, Project administration. 


\section{Acknowledgement}

This work was supported by the BMW Group. We thank the members of FC Technology Development for their support during fuel cell testing, MEA manufacturing and decal preparation. The authors are also thankful to Roland Eibl for the SEM imaging. This research did not receive any specific grant from funding agencies in the public, commercial, or not-for-profit sectors.

\section{Supplementary materials}

Supplementary material associated with this article can be found, in the online version, at doi:10.1016/j.electacta.2021.139537.

\section{References}

[1] O. Gröger, H.A. Gasteiger, J.P. Suchsland, Review-electromobility: batteries or fuel cells? J. Electrochem. Soc. 162 (2015) A2605-A2622.

[2] R.L. Borup, A. Kusoglu, K.C. Neyerlin, R. Mukundan, R.K. Ahluwalia, D.A. Cullen, K.L. More, A.Z. Weber, D.J. Myers, Recent developments in catalyst-related PEM fuel cell durability, Curr. Opin. Electrochem. 21 (2020) 192-200, doi:10.1016/j. coelec.2020.02.007.

[3] A.G. Olabi, T. Wilberforce, M.A. Abdelkareem, Fuel cell application in the automotive industry and future perspective, Energy 214 (2021) 118955, doi:10. 1016/j.energy.2020.118955

[4] P. Ren, P. Pei, Y. Li, Z. Wu, D. Chen, S. Huang, Degradation mechanisms of proton exchange membrane fuel cell under typical automotive operating conditions, Prog. Energy Combust. Sci. 80 (2020) 100859, doi:10.1016/j.pecs.2020. 100859.

[5] N. Yousfi-Steiner, P. Moçotéguy, D. Candusso, D. Hissel, A review on polymer electrolyte membrane fuel cell catalyst degradation and starvation issues: causes, consequences and diagnostic for mitigation, J. Power Sources 194 (2009) 130-145, doi:10.1016/j.jpowsour.2009.03.060.

[6] A. Rabis, P. Rodriguez, T.J. Schmidt, Electrocatalysis for polymer electrolyte fuel cells: recent achievements and future challenges, ACS Catal. 2 (2012) 864-890.

[7] L. Dubau, L. Castanheira, F. Maillard, M. Chatenet, O. Lottin, G. Maranzana, J. Dillet, A. Lamibrac, J.C. Perrin, E. Moukheiber, A. ElKaddouri, G. de Moor, C. Bas, L. Flandin, N. Caqué, A review of PEM fuel cell durability: materials degradation, local heterogeneities of aging and possible mitigation strategies, WIREs Energy Environ. 3 (2014) 540-560, doi:10.1002/wene.113.

[8] G.S. Harzer, J.N. Schwämmlein, A.M. Damjanović, S. Ghosh, H.A. Gasteiger, Cathode loading impact on voltage cycling induced PEMFC degradation: a voltage loss analysis, J. Electrochem. Soc. 165 (2018) F3118-F3131.

[9] S. Cherevko, G.P. Keeley, S. Geiger, A.R. Zeradjanin, N. Hodnik, N. Kulyk, K.J.J. Mayrhofer, Dissolution of platinum in the operational range of fuel cells, ChemElectroChem 2 (2015) 1471-1478, doi:10.1002/celc.201500098.

[10] S. Cherevko, N. Kulyk, K.J.J. Mayrhofer, Durability of platinum-based fuel cell electrocatalysts: dissolution of bulk and nanoscale platinum, Nano Energy 29 (2016) 275-298, doi:10.1016/j.nanoen.2016.03.005.

[11] F. Du, T.A. Dao, P.V.J. Peitl, A. Bauer, K. Preuss, A.M. Bonastre, J. Sharman, G. Spikes, M. Perchthaler, T.J. Schmidt, A. Orfanidi, Effects of PEMFC operational history under dry/wet conditions on additional voltage losses due to ionomer migration, J. Electrochem. Soc. 167 (2020) 144513.

[12] S.V. Venkatesan, M. Dutta, E. Kjeang, Mesoscopic degradation effects of voltage cycled cathode catalyst layers in polymer electrolyte fuel cells, Electrochem. Commun. 72 (2016) 15-18, doi:10.1016/j.elecom.2016.08.018.

[13] T. Mittermeier, A. Weiß, F. Hasché, H.A. Gasteiger, PEM fuel cell start-up/shut-down losses vs relative humidity: the impact of water in the electrode layer on carbon corrosion, J. Electrochem. Soc. 165 (2018) F1349.

[14] X. Zhang, Y. Yang, L. Guo, H. Liu, Effects of carbon corrosion on mass transfer losses in proton exchange membrane fuel cells, Int. J. Hydrog. Energy 42 (2017) 4699-4705, doi:10.1016/j.ijhydene.2016.08.223.

[15] Z.Y. Liu, B.K. Brady, R.N. Carter, B. Litteer, M. Budinski, J.K. Hyun, D.A. Muller, Characterization of carbon corrosion-induced structural damage of PEM fuel cell cathode electrodes caused by local fuel starvation, J. Electrochem. Soc. 155 (2008) B979.

[16] P.T. Yu, W. Gu, J. Zhang, R. Makharia, F.T. Wagner, H.A. Gasteiger, Carbon-support requirements for highly durable fuel cell operation, in: F.N. Büchi, M. Inaba, T.J. Schmidt (Eds.), Polymer Electrolyte Fuel Cell Durability, Springer, 2009, pp. 29-53.

[17] F. Du, J.A. Hirschfeld, X. Huang, K. Jozwiak, T.A. Dao, A. Bauer, T.J. Schmidt, A. Orfanidi, Simulative investigation on local hydrogen starvation in PEMFCs: influence of water transport and humidity conditions, J. Electrochem. Soc. 168 (2021) 74504

[18] C.A. Reiser, L. Bregoli, T.W. Patterson, S.Y. Jung, J.D. Yang, M.L. Perry, T.D. Jarvi, A reverse-current decay mechanism for fuel cells, Electrochem. Solid State Lett. 8 (2005) A273.

[19] L. Castanheira, W.O. Silva, F.H.B. Lima, A. Crisci, L. Dubau, F. Maillard, Carbon corrosion in proton-exchange membrane fuel cells: effect of the carbon structure, the degradation protocol, and the gas atmosphere, ACS Catal. 5 (2015) 2184-2194, doi:10.1021/cs501973j.
[20] A.P. Young, V. Colbow, D. Harvey, E. Rogers, S. Wessel, A semi-empirical two step carbon corrosion reaction model in PEM fuel cells, J. Electrochem. Soc. 160 (2013) F381.

[21] R. Sharma, S.M. Andersen, An opinion on catalyst degradation mechanisms during catalyst support focused accelerated stress test (AST) for proton exchange membrane fuel cells (PEMFCs), Appl. Catal. B Environ. 239 (2018) 636643, doi:10.1016/j.apcatb.2018.08.045.

[22] S. Takao, O. Sekizawa, G. Samjeské, T. Kaneko, K. Higashi, Y. Yoshida, X. Zhao, T. Sakata, T. Yamamoto, T. Gunji, T. Uruga, Y. Iwasawa, Observation of degradation of Pt and carbon support in polymer electrolyte fuel cell using combined nano-X-ray absorption fine structure and transmission electron microscopy techniques, ACS Appl. Mater. Interfaces 10 (2018) 27734-27744, doi:10.1021/ acsami.8b04407.

[23] A.P. Young, J. Stumper, E. Gyenge, Characterizing the structural degradation in a PEMFC cathode catalyst layer: carbon corrosion, J. Electrochem. Soc. 156 (2009) B913.

[24] R. Sharma, S. Gyergyek, Q. Li, S.M. Andersen, Evolution of the degradation mechanisms with the number of stress cycles during an accelerated stress test of carbon supported platinum nanoparticles, J. Electroanal. Chem. 838 (2019) 82-88, doi:10.1016/j.jelechem.2019.02.052.

[25] J.N. Schwämmlein, P.J. Rheinländer, Y. Chen, K.T. Freyer, H.A. Gasteiger, Anode aging during PEMFC start-up and shut-down: $\mathrm{H}_{2}$-air fronts vs voltage cycles, J. Electrochem. Soc. 165 (2018) F1312.

[26] J. Jung, Y.H. Chung, H.Y. Park, J. Han, H.J. Kim, D. Henkensmeier, S.J. Yoo, J.Y. Kim, S.Y. Lee, K.H. Song, H.S. Park, J.H. Jang, Electrochemical impedance analysis with transmission line model for accelerated carbon corrosion in polymer electrolyte membrane fuel cells, Int. J. Hydrog. Energy 43 (2018) 1545715465, doi:10.1016/j.ijhydene.2018.06.093.

[27] Z. Fang, A.G. Star, T.F. Fuller, Effect of carbon corrosion on wettability of PEM fuel cell electrodes, J. Electrochem. Soc. 166 (2019) F709.

[28] M. Obermaier, M. Rauber, A. Bauer, T. Lochner, F. Du, C. Scheu, Local fuel starvation degradation of an automotive PEMFC full size stack, Fuel Cells 20 (2020) 394-402, doi:10.1002/fuce.201900180

[29] B. Avasarala, R. Moore, P. Haldar, Surface oxidation of carbon supports due to potential cycling under PEM fuel cell conditions, Electrochim. Acta 55 (2010) 4765-4771, doi:10.1016/j.electacta.2010.03.056.

[30] A. Kneer, J. Jankovic, D. Susac, A. Putz, N. Wagner, M. Sabharwal, M. Secanell, Correlation of changes in electrochemical and structural parameters due to voltage cycling induced degradation in PEM fuel cells, J. Electrochem. Soc. 165 (2018) F3241.

[31] L. Castanheira, L. Dubau, M. Mermoux, G. Berthomé, N. Caqué, E. Rossinot, M. Chatenet, F. Maillard, Carbon corrosion in proton-exchange membrane fuel cells: from model experiments to real-life operation in membrane Electrode Assemblies, ACS Catal. 4 (2014) 2258-2267, doi:10.1021/cs500449q.

[32] C. Cremers, T. Jurzinsky, J. Meier, A. Schade, M. Branghofer, K. Pinkwart, J. Tübke, DEMS and online mass spectrometry studies of the carbon support corrosion under various polymer electrolyte membrane fuel cell operating conditions, J. Electrochem. Soc. 165 (2018) F3307.

[33] N. Linse, L. Gubler, G.G. Scherer, A. Wokaun, The effect of platinum on carbon corrosion behavior in polymer electrolyte fuel cells, Electrochim. Acta 56 (2011) 7541-7549, doi:10.1016/j.electacta.2011.06.093.

[34] Y. Hashimasa, Y. Matsuda, T. Shimizu, Comparison of carbon corrosion test methods for polymer electrolyte fuel cell, Electrochim. Acta 179 (2015) 119125, doi:10.1016/j.electacta.2015.03.147.

[35] R.T. White, A. Wu, M. Najm, F.P. Orfino, M. Dutta, E. Kjeang, 4D in situ visualization of electrode morphology changes during accelerated degradation in fuel cells by X-ray computed tomography, J. Power Sources 350 (2017) 94-102, doi:10.1016/j.jpowsour.2017.03.058.

[36] H. Schulenburg, B. Schwanitz, N. Linse, G.G. Scherer, A. Wokaun, J. Krbanjevic, R. Grothausmann, I. Manke, 3D imaging of catalyst support corrosion in polymer electrolyte fuel cells, J. Phys. Chem. C 115 (2011) 14236-14243, doi:10.1021/jp203016u.

[37] C. Hartnig, T.J. Schmidt, Simulated start-stop as a rapid aging tool for polymer electrolyte fuel cell electrodes, J. Power Sources 196 (2011) 5564-5572.

[38] M. Uchimura, S.S. Kocha, The impact of cycle profile on PEMFC durability, ECS Trans. 11 (2007) 1215.

[39] X.-.G. Yang, Q. Ye, P. Cheng, In-plane transport effects on hydrogen depletion and carbon corrosion induced by anode flooding in proton exchange membrane fuel cells, Int. J. Heat Mass Transf. 55 (2012) 4754-4765, doi:10.1016/j. ijheatmasstransfer.2012.04.040.

[40] B. Randrianarizafy, P. Schott, M. Gerard, Y. Bultel, Modelling carbon corrosion during a PEMFC startup: simulation of mitigation strategies, Energies 13 (2020) 2338, doi:10.3390/en13092338.

[41] N. Takeuchi, T.F. Fuller, Modeling and investigation of carbon loss on the cathode electrode during PEMFC operation, J. Electrochem. Soc. 157 (2010) B135.

[42] S.J. Ashton, M. Arenz, A DEMS study on the electrochemical oxidation of a high surface area carbon black, Electrochem. Commun. (2011), doi:10.1016/j.elecom. 2011.09.024.

[43] S. Maass, F. Finsterwalder, G. Frank, R. Hartmann, C. Merten, Carbon support oxidation in PEM fuel cell cathodes, J. Power Sources 176 (2008) 444-451, doi:10.1016/j.jpowsour.2007.08.053

[44] T. Engl, L. Gubler, T.J. Schmidt, Think different! Carbon corrosion mitigation strategy in high temperature PEFC: a rapid aging study, J. Electrochem. Soc. 162 (2015) F291. 
[45] A. Orfanidi, P. Madkikar, H.A. El-Sayed, G.S. Harzer, T. Kratky, H.A. Gasteiger, The key to high performance low Pt loaded electrodes, J. Electrochem. Soc. 164 (2017) F418.

[46] K.C. Neyerlin, W. Gu, J. Jorne, H.A. Gasteiger, Determination of catalyst unique parameters for the oxygen reduction reaction in a PEMFC, J. Electrochem. Soc. 153 (2006) A1955.

[47] G.S. Harzer, A. Orfanidi, H. El-Sayed, P. Madkikar, H.A. Gasteiger, Tailoring catalyst morphology towards high performance for low Pt loaded PEMFC cathodes, J. Electrochem. Soc. 165 (2018) F770-F779.

[48] C. Rozain, E. Mayousse, N. Guillet, P. Millet, Influence of iridium oxide loadings on the performance of PEM water electrolysis cells: part I-Pure $\mathrm{IrO}_{2}$-based anodes, Appl. Catal. B Environ. 182 (2016) 153-160, doi:10.1016/j.apcatb.2015.09. 013.

[49] A. Orfanidi, P.J. Rheinländer, N. Schulte, H.A. Gasteiger, Ink solvent dependence of the ionomer distribution in the catalyst layer of a PEMFC, J. Electrochem. Soc. 165 (2018) F1254.

[50] D.R. Baker, D.A. Caulk, K.C. Neyerlin, M.W. Murphy, Measurement of oxygen transport resistance in PEM fuel cells by limiting current methods, J. Electrochem. Soc. 156 (2009) B991.

[51] S.R. Dhanushkodi, M. Tam, S. Kundu, M.W. Fowler, M.D. Pritzker, Carbon corrosion fingerprint development and de-convolution of performance loss according to degradation mechanism in PEM fuel cells, J. Power Sources 240 (2013) 114-121, doi:10.1016/j.jpowsour.2013.03.033.

[52] T.W. Patterson, R.M. Darling, Damage to the cathode catalyst of a PEM fuel cell caused by localized fuel starvation, Electrochem. Solid State Lett. 9 (2006) A183.

[53] H. Heidary, M. Jafar Kermani, N. Khajeh-Hosseini-Dalasm, Performance analysis of PEM fuel cells cathode catalyst layer at various operating conditions, Int. J. Hydrog. Energy 41 (2016) 22274-22284, doi:10.1016/j.ijhydene.2016.08.178.
[54] H. Schulenburg, B. Schwanitz, J. Krbanjevic, N. Linse, G.G. Scherer, A. Wokaun, Quantification of platinum deposition in polymer electrolyte fuel cell membranes, Electrochem. Commun. 13 (2011) 921-923, doi:10.1016/j.elecom.2011. 05.033 .

[55] J. PERON, Y. NEDELLEC, D. JONES, J. ROZIERE, The effect of dissolution, migration and precipitation of platinum in Nafion ${ }^{\circ}$-based membrane electrode assemblies during fuel cell operation at high potential, J. Power Sources 185 (2008) 1209-1217, doi:10.1016/j.jpowsour.2008.06.098.

[56] I.M. Lifshitz, V.V. Slyozov, The kinetics of precipitation from supersaturated solid solutions, J. Phys. Chem. Solids 19 (1961) 35-50.

[57] Y. Li, D. Xiong, Y. Liu, M. Liu, J. Liu, C. Liang, C. Li, J. Xu, Correlation between electrochemical performance degradation and catalyst structural parameters on polymer electrolyte membrane fuel cell, Nanotechnol. Rev. 8 (2019) 493502, doi:10.1515/ntrev-2019-0044.

[58] N. Ramaswamy, W. Gu, J.M. Ziegelbauer, S. Kumaraguru, Carbon support microstructure impact on high current density transport resistances in PEMFC cathode, J. Electrochem. Soc. 167 (2020) 64515.

[59] J.P. Owejan, J.E. Owejan, W. Gu, Impact of platinum loading and catalyst layer structure on PEMFC performance, J. Electrochem. Soc. 160 (2013) F824-F833.

[60] T.A. Greszler, D. Caulk, P. Sinha, The impact of platinum loading on oxygen transport resistance, J. Electrochem. Soc. 159 (2012) F831.

[61] C. Stumm, M. Kastenmeier, F. Waidhas, M. Bertram, D.J.S. Sandbeck, S. Bochmann, K.J.J. Mayrhofer, J. Bachmann, S. Cherevko, O. Brummel, Model electrocatalysts for the oxidation of rechargeable electrofuels - carbon supported Pt nanoparticles prepared in UHV, Electrochim. Acta 389 (2021) 138716.

[62] P. Zihrul, I. Hartung, S. Kirsch, G. Huebner, F. Hasché, H.A. Gasteiger, Voltage cycling induced losses in electrochemically active surface area and in $\mathrm{H}_{2}$ /air-performance of PEM fuel cells, J. Electrochem. Soc. 163 (2016) F492. 